\title{
Agricultura familiar e desenvolvimento rural sustentável na Amazônia
}

Thomas Hurtienne - Professor e pesquisador do Núcleo de Altos Estudos Amazônicos da UFPA

\section{Resumo}

O artigo apresenta uma discussão crítica dos conceitos teóricos e metodológicos nos quais se baseiam as análises da pequena produção agrícola na Amazônia a partir dos anos sessenta. A visão da agricultura amazônica como agricultura itinerante, pouco produtiva, destrutora do meio ambiente e condenada ao desaparecimento devido ao avanço das grandes propriedades (o modelo do ciclo de fronteira) é contrastada com a tendência para uma consolidação da agricultura familiar baseada em sistemas de produção mais complexos, que incluem culturas permanentes, a pequena criação e gado. Essa tendência foi detectada mais claramente no Nordeste paraense, mas comprovada estatisticamente para o estado do Pará e a região Norte. Isso significa que a tese do ciclo de fronteira tem uma validez limitada, sobretudo nas regiões de colonização mais antiga. Contudo, pesquisas sobre as fronteiras mais recentes mostram sistemas de produção que se baseiam mais fortemente na pecuária no Sul do Pará e nas culturas permanentes na Transamazônica. Esses sistemas fogem à classificação simplificada de agricultura itinerante, mas representam trajetórias diferentes do Nordeste paraense.

\section{Palavras-chave}

Agricultura familiar, Amazônia, desenvolvimento sustentável

\section{Abstract}

The article presents a critical review of theoretical and methodological concepts upon which analytical works about Amazonian peasantries since the 1960s have been based. The vision of Amazon peasants as shifting cultivators with low productivity who destroy their ecological habitat and are condemned to disappear due to the advance of large landowners (the model of the frontier cycle) is contrasted with the tendency for the consolidation of family agriculture based on more complex production systems, including permanent cultures, small animal husbandry and cattle. This tendency is more clearly evident in the Northeast of Pará, but has also been statistically confirmed for the State of Pará and the Northern Region of Brazil. This means that the hypothesis of the frontier cycle has limited validity for older colonization regions. However, recent research on borders showed production systems which concentrate on cattleraising in the South of Pará and on permanent cultures in the Transamazônica region. These systems cannot simply be classified as shifting cultivation but represent different trajectories from that of the Northeast of Pará.

\section{Keywords}

Small agriculture, Amazonia, sustainable development 


\section{INTRODUÇÃO}

Os programas governamentais de desenvolvimento executados nos últimos 40 anos na Amazônia, apesar de serem insuficientes, têm mudado profundamente a estrutura econômica, demográfica e ecológica da região. A construção de rodovias, os programas de colonização oficiais e privados, a migração espontânea e os incentivos fiscais levaram ao desmatamento de mais ou menos $17 \%$ da área amazônica e à criação de paisagens agrárias variadas perto dos eixos viários, onde se concentra a maioria da população rural.

Grande parte dessa população rural é de agricultores com estabelecimentos de pequeno e médio porte (agricultura familiar) com até 200ha, sobretudo nos estados do Pará e de Rondônia. A produção desses agricultores é destinada basicamente aos mercados locais, regionais e nacionais (senão internacionais, como a pimenta-do-reino e o maracujá). Nesse segmento da agricultura, que sempre foi associado a uma agricultura "migratória" de derruba e queima com pouca estabilidade territorial e diversidade agronômica, predomina atualmente uma tendência de diversificação crescente dos sistemas de produção agrícola, incluindo de forma variável culturas perenes, pequena criação, extração vegetal e até pecuária. Pelo menos em grande parte do Pará, essa diversificação implica também uma estabilização relativa de grandes segmentos das diversas formas de agricultura familiar na terra firme, na várzea e no estuário.

Por isso, o desenvolvimento sustentável rural passa pelo desenvolvimento de sistemas de uso da terra/sistemas de produção sustentáveis adaptados às condições de produção da agricultura familiar nas vastas áreas que já se alteraram nos últimos 30 anos. Ao mesmo tempo, é necessário criar e garantir áreas de proteção ambiental para manter a cobertura florestal original.

$\mathrm{Na}$ primeira parte deste trabalho vou discutir a relação entre agricultura familiar e desmatamento, tentando demonstrar que o papel dela foi secundário em comparação com a grande pecuária.

Na segunda parte, vou apresentar um breve resumo de diversas pesquisas que mostram a diversidade das formas e trajetórias da agricultura familiar no Pará.

Na terceira e principal parte do artigo, parto de duas versões opostas sobre a trajetória da agricultura familiar na Amazônia (o ciclo de fronteira e a tese da estabilização relativa), mostro os fracos resultados da modernização agrícola forçada e tento rescontruir os esforços de descobrir os campesinatos no Pará numa maneira empírica, mas também teórica. 


\section{AGRICULTURA FAMILIAR E DESMATAMENTO: APRESEN- TAÇÃO CRÍTICA DE RESULTADO DE PESQUISA}

O redirecionamento das políticas públicas voltadas para os sistemas de uso da terra na Amazônia é uma tarefa fundamental para qualquer projeto de desenvolvimento sustentável na região. Para isso é importante dispor de uma visão abrangente e sistemática dos fatores condicionantes, da complexidade e da interdependência desses sistemas de uso da terra. Mas, por razões de tempo e espaço, este trabalho limita-se ao estudo das diversas formas da agricultura familiar na Amazônia (estabelecimentos de até 200ha), incluindo o relacionamento com o padrão de uso dos recursos florestais (mata primária e vegetação secundária). ${ }^{1}$

Essa delimitação da pesquisa justifica-se pelo fato, pouco conhecido e reconhecido, de que as formas de agricultura familiar analisadas representam os sistemas de uso da terra mais importantes do ponto de vista do número de estabelecimentos agropecuários, do pessoal ocupado, do valor da produção total e sobretudo do valor da produção vegetal na maioria dos estados do Norte, e também no Maranhão. Na Amazônia Legal, somente o Mato Grosso e, no Norte, o Tocantins mostram um perfil diferente em razão da forte modernização agrária nas últimas duas décadas e da predominância da agricultura patronal.

Nos estados do Norte, onde predomina a agricultura familiar, esse sistema somente ficou numa situação inferior à das empresas capitalistas e dos grandes latifúndios em relação à ocupação das terras privatizadas e ao valor da produção pecuária. Contrastando com a visão ainda predominante do atraso das formas diversas da agricultura familiar, os dados do Censo Agropecuário (IBGE, 1998) mostram claramente usos bem mais eficientes das terras utilizadas no caso do Pará: o valor da

\footnotetext{
${ }^{1}$ Neste trabalho, a expressão "agricultura familiar" é usada como conceito operacional para qualquer unidade de produção em que a mão-de-obra familiar predomina em mais de $90 \%$ do pessoal ocupado. Segundo Costa (1992), na Amazônia isso é válido em geral para os estabelecimentos de até 200ha, mas há exceções, como o caso do Acre, em que se deve incluir também a faixa de até 500ha. Obviamente esse exercício estatístico raramente pode distinguir as formas da agricultura familiar segundo critérios qualitativos. Para aliviar e controlar esse problema, o autor sempre trabalhou com tabulações altamente diferenciadas, o que ajudou pelo menos a compreender melhor as estruturas e tendências dos substratos da agricultura familiar: os minifúndios de até 10ha, a pequena produção de até 20ha, os módulos de colonização de 20 a 50ha nas zonas de colonização antiga e de 50 a 100ha nas zonas de mais recente colonização e as unidades de "transição" de 100 a 200ha. As tendências encontradas corresponderam, na maioria dos casos, aos resultados das pesquisas mais localizadas.
} 
produção por hectare foi de $\mathrm{R} \$ 246,00$, segundo dados do Censo Agropecuário de 1995/96, superando assim os valores atingidos pelos fazendeiros $(\mathrm{R} \$ 71,00)$ e pelas grandes empresas $(\mathrm{R} \$ 40,00){ }^{2} \mathrm{O}$ valor por pessoa ocupada foi bem mais alto nas fazendas $(\mathrm{R} \$ 3.517,00)$ e grandes empresas $(\mathrm{R} \$ 7.332,00)$ que na agricultura familiar $(\mathrm{R} \$ 834,00)$.

O que essa eficiência maior da agricultura familiar no uso da terra significa, em termos de sua participação no desmatamento, ainda é um assunto muito controvertido, sobretudo devido à falta de uma metodologia apropriada, à escassez crônica de estudos sérios e a premissas altamente duvidosas sobre o caráter da "pequena produção familiar". ${ }^{3}$

Num dos poucos trabalhos sérios, Fearnside (1995) estima a participação dos estabelecimentos de até 100ha para a Amazônia Legal (incluindo só a metade dos estabelecimentos do Maranhão e de Goiás [que em 1988 se tornou estado do Tocantins]) com base em um cruzamento dos dados do Censo Agropecuário de 1985 com os dados sobre o desmatamento nos anos de 1990 e 1991, detectados pelas imagens de satélite do Instituto Nacional de Pesquisas Espaciais (INPE). Ele estima que os estabelecimentos de até 100ha tinham, nesses dois anos, uma taxa de desmatamento anual de 0,58 e 0,45ha por estabelecimento (ou só entre 0,31 e 0,24ha, assumindo que aproximadamente 670 mil famílias de pequenos produtores não foram registrados no Censo Agropecuário de 1985). Isso contrasta com uma taxa média de 3,2 a 3,7ha para os fazendeiros médios entre 100 e 1000ha e de 18 a 29ha para os acima de 1000 ha. Como os estabelecimentos de até 100 ha representam $83 \%$ do número total e 11,1\% da área total (só no Norte são 22\%), Fearnside chegou a uma participação estimada de 30,5\% no desmatamento em 1990 e 1991, cabendo 36,5\% às fazendas médias e 33\% às grandes empresas acima de 1000ha.

\footnotetext{
${ }^{2}$ Por razões de conveniência, usamos a categorização de Costa (1992), que considera os estabelecimentos entre 200 e 5000ha como fazendas e os acima de 5000ha como grandes empresas.

${ }^{3}$ No Brasil e na discussão internacional, ainda não existe um consenso sobre como medir o desmatamento. Em princípio, o desmatamento ou, mais precisamente, o desflorestamento é entendido como a conversão ou a alteração de áreas de fisionomia florestal primária (florestas tropicais e cerradão) por ações antropogênicas (INPE, 1999). Essa definição exclui tanto a área alterada de savanas no cerrado e da vegetação secundária nas áreas de floresta tropical, como os distúrbios nas florestas primárias causados pelo corte seletivo de madeira. Apesar dessa definição, os dados do Instituto Nacional de Pesquisas Espaciais (INPE) ainda sofrem grandes limitações quanto à separação exata de áreas de vegetação secundária, que são queimadas repetidamente na agricultura de pousio, e quanto ao tamanho total da área de floresta primária alterada.
} 
Embora os pequenos agricultores até 100ha sejam responsáveis, segundo essa estimativa, por apenas 30\% do desmatamento, a intensidade na área que eles ocupam é maior do que a dos fazendeiros médios e grandes, que detêm 89\% das terras particulares na Amazônia Legal. Como a área média por estabelecimento aumenta de 18,5ha (até 100ha) para 245 ha (100 até 1000ha) e 5072ha (acima de 1000ha), a intensidade do desmatamento (área desmatada como percentagem da área total) declina, à medida que o tamanho dos estabelecimentos aumenta, de 2-3ha/ano/ $\mathrm{km}^{2}$ de terra privada para os pequenos, 1,3-1,5ha para os médios até 0,4-0,6ha para os grandes. Para Fearnside (1994), isso significa que o desmatamento aumentaria se as áreas hoje ocupadas por grandes fazendas fossem redistribuídas como pequenas propriedades. Isso indicaria a importância de usar áreas já desmatadas para uma reforma agrária, em vez de seguir o caminho politicamente mais fácil de distribuir áreas ainda com floresta.

Com uma metodologia diferente, Costa (1992) mostra dados sobre área apropriada e utilizada (incluindo as desmatadas e as capoeiras queimadas) dos Censos Agropecuários dos anos de 1980 e 1985 para o caso do Pará, uma medida de propensão para desmatar pela divisão do percentual de variação da área utilizada (interpretada como desmatada) pelo percentual da variação da área apropriada. Esse cálculo representa o ritmo de crescimento no desmatamento provocado por unidade percentual de variação na área apropriada. Para as atividades agrícolas e pecuárias dos camponeses até 200ha, ele verifica uma propensão de 0,78 , o que quer dizer que, para cada $1 \%$ de aumento na área, ampliouse o "desmatamento" em apenas 0,78\% (COSTA, 1992, p. 63). Para os fazendeiros, essa grandeza foi de 1,39 e a destes, em conjunto com as grandes empresas (acima de 5000ha), chegou a 2,23 - respectivamente o dobro e o triplo da propensão camponesa ao desmatamento. Isso reflete o fato de que, no caso dos camponeses, a taxa de crescimento da área utilizada entre 1980 e 1985 foi 20\% menor do que a da área privatizada (25,6\%), enquanto nas fazendas a área utilizada aumentou $78 \%$ mais rápido que a total (56\%). Isso se explica pela expansão mais rápida dos pastos plantados, que foram responsáveis por 67\% de toda a área desmatada em 1985, com uma participação dos fazendeiros e empresas de $80,6 \%$ nesse valor.

Todas as atividades agropecuárias dos camponeses participaram em 1985 com 38\% do "desmatamento" de florestas primárias e da vegetação secundária (as culturas temporárias, inclusive o pousio, com $21 \%$, a pecuária, com $13 \%$ e as culturas permanentes, com $3 \%$ ), mas representaram 67\% do valor da produção total (86,7\% do valor das cul- 
turas temporárias, 81,5\% das permanentes e 39\% da pecuária) e 93\% do pessoal ocupado do Pará. Em contraste, as fazendas e empresas foram responsáveis por 62\% do "desmatamento", mas por apenas $23 \%$ do valor e $7 \%$ do pessoal ocupado. Então o valor por hectare desmatado foi, no caso dos camponeses, três vezes mais alto que no caso dos fazendeiros.

Essa interpretação de Costa (1992) sofre um problema sério porque ele identifica o aumento da área utilizada (inclusive as terras em descanso) com o "desmatamento" num sentido amplo, incluindo não apenas o desmatamento de florestas primárias, mas também a derruba e a queima das vegetações secundárias (capoeiras). Com base nessa metodologia, não é possível delimitar o efeito do desmatamento da floresta.

Num estudo mais recente, o Instituto de Pesquisa Ambiental da Amazônia (IPAM) tentou esclarecer a importância das várias formas de incêndios da vegetação primária e secundária segundo as classes de tamanho dos estabelecimentos (NEPSTAD; MOREIRA; ALENCAR, 1999). Em 1994 e 1995, foi feito um levantamento de 202 propriedades em cinco municípios de diferentes partes do "arco do fogo" na região norte, que, segundo o IPAM, são representativos para os diferentes tipos de regiões de fronteira ${ }^{4} \mathrm{com}$ um regime sazonal de chuvas com pelo menos três meses de seca (menos de 100mm) ${ }^{5}$ Um resultado importante foi a distinção entre as diversas fontes do fogo na área estudada de 916.257ha: dos 76.580ha que queimaram por ano em 1994 e 1995 (8,4\% da área total), apenas 9.800 ha foram resultado de queimadas de desmatamento intencional (1\% da área total e 13\% da área queimada). Outros 15.500ha foram de incêndios florestais rasteiros ("fogo de chão na floresta" - $2 \%$ da área total e $20 \%$ da área queimada) que não aparecem nos dados do INPE. Mas a área queimada mais extensa foi resultado de fogos em áreas já desmatadas: eles cobriram 51.300ha (6\% da área total e 67\% da área queimada), dos quais 36.000ha (4\% da área total e $47 \%$ da área queimada) queimaram acidentalmente, segundo informações dos proprietários.

Outro resultado importante foi a distribuição da área queimada segundo classes de tamanho, tipo de vegetação e fontes de fogo. Os

\footnotetext{
${ }^{4}$ Os locais selecionados incluíram um grande pólo pecuário e madeireiro (Paragominas, PA), uma área de grandes fazendas (Santana de Araguaia, PA), uma região de pequenos projetos de colonização (Alta Floresta, MT), duas áreas do programa de colonização em Rondônia (Arquimedes e Ouro Preto) e uma fronteira recente (Rio Branco, AC).

${ }^{5}$ Segundo o IPAM, aproximadamente 80\% do desmatamento na Amazônia brasileira têm acontecido em regiões com uma estação seca pronunciada.
} 
valores médios para a área de desmatamento intencional foram muito mais altos do que as estimativas de Fearnside (1994): 2 ha nas propriedades de até 100ha, 9ha nas de 100 a 1000ha, 63ha nas de 1000 a 5000ha e 190ha nas de mais de 5000ha. Mas a área média dos estabelecimentos analisados também foi muito maior do que no estudo dele: 62ha (até 100ha), 414ha (100-1000ha), 2525ha (1000-5000ha) e 24.334ha (acima de 5000ha). ${ }^{6}$ Como conseqüência disso, a intensidade do desmatamento (área desmatada em porcentagem com a área total) não diverge tanto dos valores de Fearnside acima citados: 3,3\% (até 100ha), 2,3\% (100-1000ha), 2,0\% (1000-5000ha) e 1,3\% (acima de 5000ha). Com o aumento do tamanho da propriedade, diminui essa intensidade, mas a participação das classes de tamanho na área desmatada aumenta (segundo uma extrapolação dos dados para os municípios): 20\% (até 100ha), 30\% (100-1000ha), 38\% (1000-5000ha) e 12\% (acima de 5000ha). A participação da pequena produção é inferior às estimativas de Fearnside (30,8\%) e Costa (38\%), enquanto a participação das propriedades acima de 1000 ha foi $50 \%$, muito superior à estimativa de Fearnside (30,4\%).

Um terceiro resultado foi que os valores médios das áreas queimadas já desmatadas foram muito mais altos do que aqueles do desmatamento intencional: 6ha (até 100ha), 29ha (100-1000ha), 76ha (1000-5000ha) e 292ha (acima de 5000ha). Por isso, a intensidade é maior nesse caso: 11,3\% (até 100ha), 8,1\% (100-1000ha), 3,9\% (10005000ha) e 1,2\% (acima de 5000ha). A participação segundo as classes de tamanho é de 29\% (até 100ha), 43\% (100-1000ha), 20\% (10005000ha) e 8\% (acima de 5000ha).

Um resultado surpreendente da comparação entre essas duas categorias de queimada é que o desmatamento, no sentido estrito, foi, em média, muito menos importante do que as queimadas da vegetação secundária. Isso se deve a duas razões: nos municípios estudados no Nordeste paraense e em Rondônia, as queimadas em áreas já desmatadas tinham uma importância ainda acima da média, enquanto, nos municípios do sul do Pará e, de forma menos expressiva, no Mato Grosso, o desmatamento intencional superou as queimadas em áreas já desmatadas.

O quarto resultado da pesquisa contradiz ainda mais a visão comum do desmatamento na Amazônia: a área de incêndios florestais rasteiros e os fogos acidentais em áreas já desmatadas aumentaram dramatica-

\footnotetext{
${ }^{6}$ Isso reflete o fato de que os valores médios de Fearnside (1994) incluem o Maranhão, onde a presença dos minifúndios é muito alta.
} 
mente com o tamanho da propriedade - 3ha (até 100ha), 27 ha (1001000ha), 153ha (1000-5000ha) e 1343ha (mais de 5000ha). A participação por classes de tamanho revela claramente a importância dessa fonte de fogo nas propriedades maiores. Enquanto os pequenos produtores foram responsáveis por apenas 11\% da área atingida por fogos acidentais nas áreas já desmatadas e por 8\% da área de fogo de chão de floresta, os estabelecimentos entre 100 e 1000ha representaram 31\% e $33 \%$, respectivamente. Os entre 1000 e 5000ha foram responsáveis por $33 \%$ e $21 \%$, e as grandes fazendas acima de 5000 ha, por $25 \%$ e $39 \%$. No caso dos estabelecimentos acima de 1000ha, a área desses fogos acidentais supera muito a dos fogos intencionais. A importância desses fogos acidentais também foi muito mais acentuada no sul do Pará, no Mato Grosso e parcialmente no Acre, do que no nordeste do Pará e em Rondônia. No último caso, isso se deve provavelmente à predominância da agricultura familiar. Se os autores tivessem escolhido outros municípios do Nordeste paraense, com características mais representativas para essa região do que o município de Paragominas, o estudo teria mostrado provavelmente que fogos acidentais ocorrem com muito menos freqüência.

Infelizmente esses resultados diferenciados não receberam a atenção necessária nos documentos oficiais sobre o problema do desmatamento, nem no âmbito nacional nem no internacional. Devido a uma metodologia inadequada, o INPE sugeriu, na apresentação do material segundo classes de tamanho de desflorestamento em 1995 e 1996, que $61 \%$ ou 53\% do desmatamento ocorreram em áreas de até 100ha, o que foi várias vezes confundido, até propositadamente, com as classes de tamanho de propriedade. Segundo os dados para os anos de 1996 e 1997, as médias e grandes derrubadas cresceram mais, sobretudo em áreas contínuas com 200 a 500ha, acima de 1000ha e na região de contato. Apesar da relativa redução em importância, o desmatamento de áreas inferiores a 50ha foi ainda alto nas zonas de contato e na floresta aberta (NOBRE, 1999; INPE, 1999).

Essa interpretação muitas vezes errada dos dados do INPE na esfera pública está na verdade profundamente enraizada na visão, ainda predominante, da pequena produção familiar na Amazônia, que é identificada como uma agricultura "migratória" de corte e queima de culturas temporárias voltadas para a mera subsistência, pouco expressiva economicamente, a grande vilã ecológica e sobretudo um problema social. Infelizmente essa visão ainda não foi abandonada por entidades que são importantes na definição dos rumos das políticas públicas para a Amazônia. Apenas por razões de ilustração, vou 
referir-me sobretudo à argumentação de autores do Centro de Pesquisa Agropecuária do Trópico Úmido (CPATU) da Empresa Brasileira de Pesquisa Agropecuária (EMBRAPA) em Belém que, apesar de muitos estudos que apontam o contrário, ainda compartilham essa visão simplificadora e homogeneizante em documentos mais gerais (SERRÃO; HOMMA，1993; SERRÃO，1995a，1995b; SERRÃO; NEPSTAD; WALKER, 1998; KITAMURA，1982, 1994; HOMMA, WALKER et al., 1998).

Esses autores tendem a identificar a pequena produção familiar (até 50 ha) com a agricultura migratória como o sistema ainda mais importante de uso da terra na Amazônia, responsável por pelo menos 80\% da produção de alimentos da região (SERRÃO, 1995a, p. 74). Eles assumem, aparentemente com base nos dados dos Censos Agropecuários de 1985 e 1995/96, que entre 500.000 e 600.000 pequenos agricultores produzem, em praticamente toda a região amazônica, principalmente culturas temporárias no sistema tradicional de corte e queima. Nesse sistema os produtores fazem desmatamentos de floresta densa ou de capoeira para cultivar em média 2 ha por dois anos consecutivos, deixando depois essa área em pousio por aproximadamente 10 anos. Por isso eles precisam - num processo que pode ser chamado de "desmatamento silencioso" (HOMMA, 1989) - de pelo menos 10 ou 12 milhões de hectares para atender à demanda anual de 500.000 ou 600.000ha. Numa versão mais suave, isso significa devido ao encurtamento do pousio - "apenas" sérios problemas de sustentabilidade para esse sistema, que era tão adequado ao meio ambiente em outros contextos históricos (SERRÃO, 1995a e b, p. 74). Outras versões chegam à conclusão bem mais drástica de que é possível "afirmar que a maior parte dos desmatamentos são atualmente realizados por este segmento de pequenos produtores" (HOMMA; WALKER et al., 1998, p. 133).

Qual é a base empírica dessas conclusões? Obviamente os dados dos Censos Agropecuários sobre o número dos estabelecimentos de até 50 ha (no caso do Censo de 1995, em 1985 só constam os de 10-50ha). Incluindo todo o Maranhão e não somente as áreas que fazem parte da Amazônia Legal, chega-se a 616.704 estabelecimentos de até 50ha (276.708 na região Norte, 32.044 no Mato Grosso e 308.752 no Maranhão), o que corresponde à estimativa mais recente dos autores. Como se deveria considerar apenas a metade dos estabelecimentos do Maranhão, esse número reduz-se para 464.463 estabelecimentos.

Mas isso não é o ponto fundamental. Levando a sério os dados do Censo, os estabelecimentos onde predominam as culturas temporárias 
foram apenas 295.327 (179.538 no Norte, 15.598 no Mato Grosso e a metade dos 200.382 no Maranhão), com uma área total de 3,57 milhões de hectares (0,625 no Norte, a metade dos 0,482 no Maranhão, mais 2,46 milhões no Mato Grosso). Considerando as áreas com culturas temporárias em todos os estabelecimentos, chega-se a uma área ainda maior de 4,4 milhões de hectares (1,24 no Norte, 2,78 no Mato Grosso, a metade dos 0,741 no Maranhão). Mas os estabelecimentos de até 50 ha ficaram só com 16,7\% dessa área, quer dizer, 734.965 ha (457.781 no Norte, 72.238 em Mato Grosso e a metade dos 939.911ha no Maranhão), em 367.815 estabelecimentos (207.867 no Norte, só 12.613 no Mato Grosso e a metade dos 298.669 no Maranhão).

Nota-se que não é mais possível identificar a área das culturas temporárias, como os autores da EMBRAPA e outros fazem, com a agricultura migratória de pequeno porte (até 50ha), porque ela representa apenas uma fração pequena dessa área: 36,8\% no Norte, 27\% no Maranhão, 2,6\% no Mato Grosso e, no total para a Amazônia Legal, somente $16,7 \%$, devido ao grande peso da produção modernizada de grande porte no Mato Grosso.

Mas também não se deve reduzir a produção agropecuária nos estabelecimentos de até 50 ha aos cultivos temporários no sistema de corte e queima, porque os dados do Censo mostram que a participação das culturas anuais no valor de produção total dos estabelecimentos de até 50ha alcançou 45\% no Norte, 39\% no Maranhão e 23\% no Mato Grosso. Também quando se leva em conta, como Fearnside (1994) e o próprio Instituto Brasileiro de Geografia e Estatística (IBGE), que uma quantidade desconhecida de estabelecimentos de posseiros não foi contada no Censo, fica difícil chegar aos valores dos autores da EMBRAPA.

Uma análise mais aprofundada mostra que não existe uma correlação clara entre a expansão da agricultura familiar e o desmatamento, porque as diversas formas de uso da terra estão ligadas a graus diferentes de sustentabilidade ambiental. Isso se deve sobretudo ao fato de que a maioria dos estabelecimentos da agricultura familiar não pode ser mais considerada como agricultura migratória de derruba e queima (shifting cultivation), mas como sistemas de produção agrícola complexos que incluem culturas perenes, árvores frutíferas, extração vegetal de produtos florestais não-madeireiros (açaí, cupuaçu, castanha-dopará), a pequena e a grande criação (COSTA, 1992, 1994; HURTIENNE, 1998). Isso também é resultado dos estudos da equipe da EMBRAPA sobre a Transamazônica (WALKER et al., 1998).

Outros estudos, como os do projeto SHIFT Capoeira, mostram também que essa agricultura de derruba e queima nem sempre tem efeitos 
tão desastrosos para o meio ambiente, como é normalmente assumido (DENICH; KANASHIRO; VLEK, 2000). Isso se deve aos efeitos pouco conhecidos da capoeira, que pode garantir a manutenção das funções básicas dos ecossistemas naturais.

Igualmente veremos que a expansão da pecuária nas fronteiras recentes nem sempre implica a contínua derrubada de mata primária como tendência principal, porque, nas unidades de produção com terras suficientes, como na Transamazônica, a broca e a queima de capoeiras podem ser mais vantajosas do ponto de vista econômico e ecológico (WALKER et al., 1998; MORAN et al., 1996).

Comparando as novas formas da agricultura familiar com as mais velhas, das populações chamadas tradicionais, como grupos indígenas, ribeirinhos e extrativistas, deve-se levar em conta que não existe uma linha divisória clara entre essas formas de "produção familiar": os extrativistas também têm roças de culturas temporárias, árvores frutíferas, aves, porcos e crescentemente o gado. Eles podem ser também responsáveis por um desmatamento em pequena escala e por uma diminuição significativa da biodiversidade (NEPSTAD, 1997). Mas, por outro lado, muitos colonos já integram uma boa parte do conhecimento tradicional sobre a maneira de proteger o solo com sistemas agroflorestais (o caso mais espetacular é o projeto RECA, na fronteira entre Acre e Rondônia).

Uma visão mais diferenciada da relação entre a expansão da agricultura familiar e o desmatamento deveria também ser importante para os diversos programas das agências internacionais e nacionais que pretendem frear o desmatamento na região. Preocupadas com a função da floresta amazônica para o clima global, as propostas das agências internacionais e nacionais, em geral, limitaram-se ao apoio a grupos indígenas, seringueiros e ribeirinhos, identificando os sistemas de uso das terras tradicionais desses grupos (sistemas agroflorestais e extrativistas) como os únicos com uma alta sustentabilidade ecológica. No entanto, a grande maioria dos produtores agrários no campo é identificada com a noção da shifting cultivation (agricultura itinerante) que - segundo a percepção dominante - tornou-se cada vez mais insustentável do ponto de vista ecológico devido ao declínio da fertilidade natural do solo causado pelo aumento da pressão demográfica e pelo encurtamento do pousio. Essa visão simplificada das agências internacionais foi reforçada pela persistência desse enfoque também nas instituições nacionais e regionais, como a EMBRAPA, a Empresa Brasileira de Assistência Técnica Rural (EMATER), a Superintendência de Desenvolvimento da Amazônia (SUDAM) e outras. O grande perigo 
dessa visão superficial é que ela pode, como no passado, tentar justificar que apenas uma agricultura intensiva em capital e insumos externos pode ser capaz de conciliar o desenvolvimento econômico em áreas degradadas com a proteção da floresta amazônica.

Nos últimos anos, essa percepção começou a mudar no âmbito político-institucional, em decorrência de pressões de atores sociais, como os sindicatos dos trabalhadores rurais, ou de pesquisas isoladas sobre diversas microrregiões, também dentro da própria EMBRAPA, o que levou a uma revalorização da pequena produção no processo do desenvolvimento agrário (ABRAMOVAY, 1997). Vários programas foram lançados para fortalecer a agricultura familiar, como recentemente o Programa Nacional de Fortalecimento da Agricultura Familiar (PRONAF). Em âmbito nacional, essa nova tendência foi parcialmente efeito dos fracos resultados da modernização agrária em unidades grandes e médias com altos insumos externos, sobretudo depois da retirada dos subsídios. O que sempre foi percebido como pequena produção de subsistência sem grandes chances de aumentar sua produtividade é reinterpretado como um campo bem mais diverso de formas de agricultura familiar com possibilidades econômicas também diversas. Apesar disso, a continuidade da modernização das empresas agrárias grandes e médias e dos latifúndios demonstra que essa mudança paradigmática é somente parcial.

A reformulação e o redirecionamento das políticas agrárias nos vários níveis administrativos são limitados até hoje pelo fato de que a grande diversidade dos sistemas de uso da terra não é considerada de maneira sistemática. O grande desafio atual e futuro é atingir uma compreensão mais diferenciada das diversas formas da agricultura familiar na terra firme, na várzea e no estuário. Essa compreensão deve levar em conta as condicionantes agroecológicas, socioeconômicas, socioculturais e a idade da colonização. Uma dimensão muitas vezes esquecida mas fundamental é a político-institucional: na verdade, são os fatores políticos que explicam as diferenças no desempenho econômico entre regiões de colonização muito similares, como Marabá e a Transamazônica, ambas no sul do Pará (HURTIENNE, 1998).

Dessa maneira, pode-se analisar também até que ponto a dinâmica da agricultura familiar nas áreas de colonização antiga, como a Zona Bragantina, onde domina uma vegetação secundária em um sistema de pousio e restos pequenos da mata primária e secundária madura, difere daquela que se instalou em outras áreas da Amazônia há 50 anos (Capitão Poço, Irituia) ou 20 anos (Marabá, Transamazônica, Rondônia). Estas últimas referem-se às várias áreas da 
colonização oficial e espontânea, que dispõem ainda de reservas florestais significativas.

Mas a diversidade da agricultura familiar na Amazônia não se explica somente por meio dos fatores socioeconômicos e políticos, mas também com base nos fatores agroecológicos ainda pouco compreendidos. Os resultados de pesquisas biológicas feitas na Zona Bragantina, em Paragominas e Capitão Poço mostram que a agricultura de pousio representa um sistema de uso da terra diferente do que pressupõe a estereotipada noção da agricultura itinerante. Isso acontece sobretudo quando se considera de maneira sistemática o papel fundamental da capoeira para a manutenção dos fluxos de nutrientes e das funções ecológicas básicas, como o ciclo hidrográfico e a biodiversidade.

Por existir uma densidade demográfica e uma integração ao mercado relativamente altas, não se pode falar mais somente de uma agricultura de subsistência miserável nas margens das fronteiras agrárias ou, como alternativa, de uma agricultura comercial de médio porte com fortes insumos externos. O que se desenvolveu nas zonas de colonização mais antigas na terra firme do Pará (Zona Bragantina, depois a Guajarina), mas também na Transamazônica, são sistemas de produção diversificados, que conseguiram ultrapassar alguns dos limites inerentes a uma agricultura migratória ou itinerante: uma certa estabilização das agriculturas familiares num nível socioeconômico que - apesar de não satisfatório - pelo menos consegue limitar migrações expressivas para as cidades e novas fronteiras agrárias. Essa estabilização relativa deuse também dentro de sistemas de uso da terra que utilizam somente poucos insumos externos, a não ser o uso abundante da energia solar para o sistema de pousio. Os limites inerentes a essa agricultura de pousio (seu encurtamento enfraquece a fertilidade já limitada do solo) foram superados pela integração sucessiva de culturas perenes ou do gado, o que implica novos limites, mas também oportunidades para um sistema sustentável.

Apesar de todas as incertezas quanto à sustentabilidade a médio e longo prazos desses sistemas de produção familiar na região, pode-se levantar a hipótese de que essas formas de uso da terra foram ou podem ser bem mais sustentáveis ecológica, econômica e socialmente do que foi percebido pelos cientistas naturais e pelas agências políticas na Amazônia, no Brasil e no âmbito internacional. Além disso, os sistemas de produção familiar oferecem também possibilidades de integrar cultivos (agro)florestais e pecuária, facilitando assim a tração animal (como substituto do uso de tratores). 
Isso implica também que um redirecionamento das políticas agrárias em favor da agricultura familiar e do desenvolvimento rural sustentável pode ter uma gama de possibilidades bem mais abrangente do que foi convencionalmente pensado.

\section{A DIVERSIDADE DAS FORMAS E TRAJETÓRIAS DA AGRICULTURA FAMILIAR NO PARÁ: UMA COMPARAÇÃO INICIAL}

O projeto inicial do artigo partiu da idéia de utilizar os dados de uma pesquisa sobre a sustentabilidade da pequena produção na Zona Bragantina, especialmente Igarapé-Açu, no âmbito do programa SHIFTCNPq do qual o autor participou como coordenador, como base para um trabalho de comparação de fronteiras diversas fora da área de colonização antiga na Zona Bragantina. Uma pergunta central foi se as tendências identificadas na Zona Bragantina têm importância para o futuro desenvolvimento nas outras fronteiras ou se as condições específicas de formação dessas fronteiras mais recentes resultam em trajetórias diferentes (HURTIENNE, 1998, 2000).

Num primeiro passo, foi realizada uma comparação sistemática dos materiais existentes na forma de resultado de pesquisas representativas (Capitão Poço, Irituia, Uraim), de diagnósticos rápidos (Marabá, Transamazônica, Santarém) e de trabalhos sobre assentamentos (Rondônia). Alguns resultados dessa comparação são descritos abaixo.

1. As formas particulares nas quais se desenvolveram as fronteiras foram resultado de uma complexa interação de fatores condicionantes, entre os quais ressalta o papel das políticas agrárias com as características específicas da ocupação territorial. Os diagnósticos estudados analisam essas diferenças apenas de forma rudimentar.

2. Devido às grandes divergências na idade e na composição das fronteiras (Capitão Poço há 45 anos, Marabá/Transamazônica há 25 anos) e conseqüentemente à existência de reservas florestais ainda significativas, a economia de pousio - que foi mais bem estudada na Zona Bragantina - tem um peso diferente. Mas isso não impede que o ciclo de pousio tenha grande semelhança com o da Zona Bragantina. Contrariamente à visão comum, o uso da capoeira como fator natural da preservação da fertilidade do solo ainda é importante nas fronteiras com uma participação mais alta de culturas perenes (Capitão Poço e Transamazônica). 
3. Um fator que diverge muito é o papel da pecuária de pequeno porte, que é bem mais importante em Marabá, na Transamazônica e em Capitão Poço (parcialmente), do que na Zona Bragantina. Isso se choca com o modelo do ciclo da fronteira, que pressupõe uma tendência geral que termina na pecuarização para todas as fronteiras agrárias.

4. A evolução dos sistemas de produção não segue só uma trajetória, como pressupõe o modelo de ciclo de fronteira ou a interpretação mais evolutiva da complexificação. Foram identificadas várias trajetórias que não seguem uma tendência linear e dependem das condições iniciais divergentes e da complexa interação dos fatores condicionantes. A análise dessa interação ainda deve ser aprofundada com os levantamentos no campo.

Para aprofundar essas hipóteses, tiradas da comparação das diversas pesquisas dentro do Pará, mas sobretudo para compará-las com as trajetórias aparentemente diferentes na Amazônia ocidental, foi realizada uma análise ampla sobre a dinâmica da população rural e a ocupação das terras no Pará e nos diversos estados da Amazônia Legal, usando os dados dos censos demográficos e agropecuários. Sobretudo os resultados, publicados recentemente, do Censo Demográfico de 1996 mostram que a dinâmica migratória para a Amazônia já acabou e que a população rural recuou ou estagnou na maioria dos estados nos anos 90, fora do Pará. Isso correspondeu em parte à diminuição do número dos estabelecimentos e da área da agricultura familiar. Esses resultados surpreendentes exigiram uma análise mais aprofundada da dinâmica populacional e da ocupação das terras no auge da imigração e no seu declínio.

Essa análise do material dos censos permitiu verificar as hipóteses desenvolvidas com base nas poucas pesquisas feitas no Nordeste e no Sul do Pará, no âmbito dos estados, das meso e microrregiões e dos municípios. Na comparação com os dois últimos censos, foram detectadas ainda algumas tendências não percebidas nas análises anteriores.

\section{AGRICULTURA FAMILIAR E DESENVOLVIMENTO: PROBLEMAS CONCEITUAIS E METODOLÓGICOS NO CONTEXTO HISTÓRICO DA AMAZÔNIA}

O desafio para qualquer análise da dinâmica da pequena produção familiar na Amazônia e da sua sustentabilidade reside na dificuldade de considerar a grande diversidade das formas de produção familiar no campo: 
- durante séculos, extrativistas tradicionais e agricultores itinerantes, como os grupos indígenas, caboclos e ribeirinhos, foram os grupos populacionais mais importantes na Amazônia rural - o segmento desses camponeses agroextrativistas ainda é importante na Zona Bragantina;

- com a construção da ferrovia na Zona Bragantina no começo do século, estabelece-se um campesinato agrícola com base numa agricultura itinerante de pousio, já altamente orientado para o suprimento do mercado de Belém - nos anos 40 e 50, esse processo de colonização estendeu-se à região Guajarina (Capitão Poço e Irituia);

- a grande imigração de colonos do Nordeste e do Sul do Brasil depois da abertura da Amazônia através dos novos eixos rodoviários, os programas de colonização oficial e os grandes projetos foram a base para a formação de um campesinato mais novo.

Neste trabalho, os conceitos de agricultura camponesa e agricultura familiar são usados como sinônimos porque ambos se referem à predominância da força de trabalho familiar na produção e à indivisibilidade de decisões de produção e de consumo. Na região Norte, o tamanho dos estabelecimentos com uma participação do trabalho familiar acima de 90\% na força de trabalho usada alcança em geral até 200 ha (COSTA, 1992). A respeito da relação dos produtores agrícolas com os mercados de produtos e fatores, esses conceitos têm conotações diferentes: camponeses estão só parcialmente integrados em mercados de produtos e fatores interligados e altamente personalizados, enquanto produtores familiares estão altamente integrados em mercados anônimos e separados (FRIEDMANN, 1980; ELLIS, 1993; ABRAMOVAY, 1992; VEIGA, 1991). Essa distinção entre camponeses e agricultores familiares é normalmente usada para distinguir a agricultura do Norte, com poucos insumos externos, da agricultura do Sul do Brasil, mais capitalizada. Porém, até no caso da Amazônia, podemos encontrar exemplos para ambos os tipos de agricultura. Infelizmente, essa distinção não é comum no debate atual sobre a agricultura do Norte, já que a pequena produção é identificada com a agricultura familiar ou com a produção familiar, sem que sejam especificados os critérios para essa denominação.

Essa ambigüidade dos conceitos adotados reflete, num certo sentido, uma dificuldade real de compreender a estrutura e a dinâmica diferente de uma agricultura de pousio, que ainda usa as técnicas tradicionais de corte e queima para a fertilização do solo e que se afasta, por isso, do tipo de agricultura permanente encontrada no Sul e, porém de 
outra forma, do Nordeste do Brasil. Quase toda a literatura agronômica, agroeconômica e agrossociológica no Brasil refere-se mais a esta última. A discussão internacional também não avançou muito além desse estado de arte nos anos 60 - representado pelas obras de Boserup (1965) e Ruthenberg (1980) - no entendimento de uma agricultura de pousio relativamente estável, que deveria ser distinguida da agricultura migratória de derruba e queima (a shifting cultivation). Por isso, parece compreensível, à primeira vista, que a discussão sobre os sistemas de uso da terra na Amazônia ficou muito presa a conceitos puramente descritivos, pejorativos ou inadequados. Daí a importância de uma recuperação e de uma reconstrução histórica desses conceitos para avançar na pesquisa.

Mas, além dessa dificuldade real, dever-se-á também considerar que, num segundo plano, as categorias usadas na Amazônia ainda estão muito enraizadas numa visão depreciativa do mundo rural, que desde a colonização raras vezes foi entendido numa forma não ideológica (COSTA, 1992). Por essa razão, a desconstrução de categorias como extrativismo, agricultura migratória, caboclos é sumamente importante para superar as visões do mundo não adequadas à diversidade social da Amazônia. Essa desconstrução também é válida para a tendência oposta, atualmente muito em voga, de valorizar esses conceitos como mais adequados para a sustentabilidade ambiental global e amazônica. Por outro ângulo, isso implica também a necessidade de reintroduzir categorias aparentemente estranhas à realidade amazônica, como campesinato, vilas agrárias e agricultura familiar, que transcendem a noção da pequena produção familiar de subsistência.

Fora esses problemas reais e ideológicos com as categorias usadas, dever-se-á, num terceiro plano, lembrar também que o uso depreciativo ou pelo menos "caricato" de conceitos descritivos, como pequenos produtores, economia de subsistência e ciclo de fronteira, foi, até os anos 80, também um problema geral na discussão brasileira sobre o destino da pequena produção agrícola. A pequena produção agrícola sempre foi tratada mais como um fator de atraso num processo aparentemente irreversível de modernização agrária em grandes empresas ou só como um problema social devido ao passado colonial escravista, a tradições populistas sobretudo urbanas, a visões anticamponesas da esquerda tradicional, à forte predominância das oligarquias e burguesias rurais e à dinâmica contínua das fronteiras agrárias (VEIGA, 1998). A revalorização econômica da pequena produção só aconteceu a partir do fim dos anos 80, com a nova bandeira da agricultura familiar como fator imprescindível de qualquer economia mo- 
derna no âmbito acadêmico, mas sobretudo no campo dos novos movimentos camponeses (ABRAMOVAY, 1997). Infelizmente, a absorção dessa nova bandeira no discurso político até na Amazônia foi bem mais rápida do que a compreensão verdadeira do novo significado desse conceito em relação aos velhos conceitos. Por isso, a simples troca de palavras por razões políticas não resolve o problema de uma interpretação mais profunda e coerente da estrutura e da dinâmica de sistemas de produção que seguem outra lógica econômica e social que não a das empresas capitalistas. Isso ainda é um problema sério nas regiões do Brasil com uma agricultura permanente. Mas, na Amazônia, isso implica um desafio maior devido à grande diversidade das formas de produção familiar e aos problemas mais sérios da sustentabilidade ambiental e econômica.

\subsection{Duas visões opostas da "pequena produção": o ciclo de fronteira da agricultura itinerante versus a estabilização relativa da agricultura familiar por meio da complexificação}

A visão homogeneizadora da pequena produção rural como agricultura itinerante, migrante ou nômade foi compartilhada por diferentes vertentes:

- os enfoques dominantes da modernização agrária acusaram os camponeses de serem agricultores itinerantes pouco eficientes e responsáveis por um grande impacto destrutivo sobre os ecossistemas primários;

- os críticos das políticas de modernização identificavam-nos como as vítimas nas várias fronteiras agrárias, condenados à expulsão pela pecuária ou por outros sistemas de produção modernos;

- os defensores da conservação da floresta tropical, incluindo muitas ONG e o Rain Forest Unit do Banco Mundial, consideravam-nos basicamente como nutrient miners indiferentes aos impactos destrutivos das suas ações.

A visão dominante do ciclo da fronteira considera esses sistemas de produção camponesa que funcionam somente com base em culturas anuais no sistema de derruba e queima como altamente insustentáveis, tanto no nível econômico como no ecológico. Os condicionantes ecológicos (solos pobres e ácidos, chuvas fortes com alto potencial de lixiviação, invasão das ervas daninhas e pragas), econômicos (falta de infraestrutura, alto custo de comercialização devido à interligação dos mercados de fatores e produtos por via de venda na folha, falta de acesso ao crédito e à assistência técnica), jurídicos (falta de títulos de propriedade) e sociais (tradições agrícolas não adaptadas) somente permitem sis- 
temas de produção simples e de curta permanência devido à queda da fertilidade do solo e à demanda de terra já derrubada por novos agentes mais capitalizados.

Essa posição foi justificada com o modelo ecológico clássico da floresta tropical da Amazônia (para uma discussão extensa, ver HURTIENNE (1997)). Contudo, resultados recentes da pesquisa em ecologia tropical na Amazônia Oriental (DENICH; KANASHIRO; VLEK, 1995; NEPSTAD et al., 1994) mostram que o modelo clássico precisa ser revisado em vários aspectos que estão relacionados diretamente com a sustentabilidade dos sistemas de produção (por exemplo, o papel das raízes profundas da vegetação secundária na reciclagem da água e dos nutrientes de níveis de solos mais profundos).

Contrapõe-se a essa visão dominante a tese de uma estabilização relativa dos camponeses nas diversas fronteiras no Pará (COSTA, 1994). Com dados secundários e primários, foi mostrado que a pequena produção baseia-se cada vez mais na complexificação dos sistemas de produção (integração pelo menos econômica de culturas perenes, pequena criação e gado) e, por isso, na superação do shifting cultivation como forma predominante.

Essa contradição aparente nas perspectivas de análises reflete-se também em tendências aparentemente contraditórias na história de ocupação:

- nas zonas de colonização mais antigas como a Zona Bragantina e seu prolongamento até a região Guajarina, no Nordeste paraense, nos anos 50 e 60, antes da construção da Belém-Brasília (Capitão Poço, Irituia), onde prevalece a tendência à estabilização relativa;

- nas zonas de colonização mais recentes, depois da Belém-Brasília, na Amazônia Ocidental (Rondônia, Mato Grosso) e no Sul do Pará (Marabá, Transamazônica), onde o ciclo da fronteira provavelmente tem mais validade.

Este trabalho mostra com mais detalhes em que medida essas duas tendências, presentes em qualquer fronteira, entrelaçaram-se, predominando sempre uma delas, dependendo da história da ocupação, das políticas públicas e das condições agroecológicas.

\subsection{O ciclo de fronteira e o fracasso da modernização agrária}

Na fase da modernização agrícola forçada nos anos 70, a pesquisa socioeconômica limitou-se basicamente à análise da expansão dos grandes estabelecimentos e da presença supostamente transitória de colonos 
na fronteira agrícola que praticavam uma agricultura de subsistência (VELHO, 1976; FOWERAKER, 1981; BECKER, MIRANDA, MACHADO, 1990).

Transferindo as experiências do Sul (sobretudo do Paraná) para o Norte, partia-se de um ciclo típico de fronteira, no qual os pequenos agricultores logram, na primeira fase de ocupação - apesar de terem títulos de propriedade rural inseguros - tanto assegurar sua subsistência com base na slash-and-burn ou shifting cultivation, que segue à derrubada da floresta primária, como abastecer os centros urbanos com alimentos baratos. Numa segunda fase, o sucesso inicial é minado paulatinamente pelo capital mercantil explorador, títulos de propriedade inseguros, infra-estrutura insuficiente, uma política agrária dirigida aos grandes estabelecimentos e pela queda dos rendimentos devido aos solos pobres em nutrientes depois da derrubada da floresta primária. No final do ciclo da fronteira, a maioria dos colonos é expulsa ou marginalizada pela grande pecuária e pelas plantações de culturas perenes. No caso mais auspicioso, essa expulsão é precedida pela venda da terra, transformada pelo colono em pastagem, aumentando dessa maneira o seu valor. A estrutura fundiária polarizada das regiões de colonização antiga reproduz-se na forma do complexo latifúndio-minifúndio, e a maioria dos colonos migra para a próxima fronteira ou para as cidades. ${ }^{7}$

Esse ciclo de vida na fronteira agrícola foi estudado detalhadamente em Rondônia, Mato Grosso e no Sul do Pará. Durante muito tempo, esse ciclo marcou as análises da pequena agricultura na Amazônia (HÉBETTE; ACEVEDO, 1979; MARTINE; 1990; COY, 1988; COY, 1996; AUBERTIN, 1988; LÉNA; OLIVEIRA, 1992). Tanto na perspectiva da economia política (FOWERAKER, 1981) como em sua versão neoclássica do nutrient mining (OZÓRIO DE ALMEIDA, 1992; OZÓRIO DE ALMEIDA et al., 1992; SCHNEIDER, 1995), esse ciclo foi considerado como uma tendência geral marcando a Amazônia, dado que a crescente construção de estradas garantia uma dis-

\footnotetext{
${ }^{7}$ Outra formulação desse modelo do ciclo de vida da frente pioneira, deduzido das experiências no Sul, sobretudo do Paraná, pressupõe em geral quatro fases: primeiro, uma fase de ocupação caracterizada pela imigração de grupos expulsos de outras regiões que vêem na fronteira um espaço de sobrevivência; segundo, uma fase de diferenciação, quando esses grupos são cada vez mais substituídos por grupos mais capitalizados, que contribuem com processos de concentração e expulsão por via da venda da terra; terceiro, uma fase de incorporação dos capitalizados com a transformação de lavouras em pasto, o esvaziamento populacional das áreas rurais e o crescimento das cidades; finalmente, a fase de decadência e degradação da pecuária extensiva devido ao esgotamento dos solos ou à erosão e à predominância das atividades urbanas nas cidades pioneiras. Esse modelo, tirado dos estudos de Coy (1987, 1996) sobre Rondônia, pode ser encontrado nos trabalhos de Martine (1990), Foweraker (1981) e Ozório de Almeida (1992).
} 
ponibilidade ilimitada de terras baratas. Junto à imagem pouco diferenciada da shifting cultivation nômade, essa visão do pequeno agricultor na Amazônia caracteriza até hoje documentos e análises oficiais nacionais e internacionais (WORLD BANK, 1992; SERRÃO; HOMMA, 1993). Na sua variante neoclássica, no entanto, já foi demonstrada a possibilidade de uma parte da pequena agricultura se estabilizar em estabelecimentos médios consolidados sobretudo na Transamazônica (OZÓRIO DE ALMEIDA; CAMPARI, 1995; WALKER; HOMMA et al., 1998). Também de maneira similar, trabalhos mais recentes, com enfoque na economia política no âmbito do Centro AgroAmbiental do Tocantins (CAT) - Laboratório Sócio-Agronômico do Tocantins (LASAT) em Marabá, documentam a possibilidade de uma acumulação patrimonial por meio do plantio e da venda de pastagem ou por estoques de gado (REYNAL et al., 1996).

Contudo, essa consolidação da pequena agricultura parecia uma exceção numa tendência geral à polarização fundiária e à instabilidade da agricultura familiar. Ficou sem explicação o fato de esse ciclo de fronteira aparentemente ter uma validade apenas limitada, tanto nas regiões clássicas de colonização antiga, como a Zona Bragantina, quanto no prolongamento dessa fronteira para o sul do Nordeste paraense (Tomé-Açu, Irituia e Capitão Poço).

Um enfoque metodológico que prioriza a análise da dinâmica dos sistemas de produção da agricultura, vinculando fatores estruturais agroecológicos e socioeconômicos aos processos de decisão característicos da agricultura familiar, tem de rever a insuficiência de pesquisas e das categorias usadas na Amazônia.

Essa situação atinge tanto a caracterização dos agroecossistemas de pequeno porte presentes nas regiões de colonização antiga e nas de fronteira agrícola mais recente, quanto a avaliação da sustentabilidade econômica e ecológica desses agroecossistemas em comparação com outros sistemas de uso agrícola da terra. Um dos problemas mais importantes é o uso até hoje pouco diferenciado do conceito da "agricultura itinerante" ou "nômade" (shifting cultivation) para caracterizar uma grande variedade de sistemas agrícolas (KITAMURA et al., 1983; SERRÃO, HOMMA, 1993; WORLD BANK, 1992; BURGER, KITAMURA, 1987). Sob esse conceito, bastante vago, abrigam-se sistemas tão diferentes como os dos povos indígenas, dos caboclos e ribeirinhos, dos colonos da Zona Bragantina e dos migrantes vindos do Nordeste e do Sul brasileiro para a fronteira agrícola, como se fossem um único sistema de uso da terra.

A agricultura itinerante - vista como o símbolo de uma economia primitiva da idade da pedra - foi responsabilizada durante muito tempo 
pela falta de desenvolvimento socioeconômico na Amazônia (WAGLEY, 1953). Por isso, a política oficial de modernização procurou repetidamente introduzir uma agricultura "ordenada" segundo o padrão dominante na Europa ou no Sul brasileiro (COSTA, 1992). Como esses programas de modernização fracassaram - de maneira mais específica na Transamazônica -, foi ganhando espaço a idéia da revalorização da combinação tradicional da extração de produtos florestais com uma agricultura de derruba e queima como é praticada pelos grupos indígenas e pelos caboclos. Essa combinação é sustentável nos níveis ecológico e econômico, pelo menos sob condições de baixa densidade demográfica, baixo nível de integração ao mercado e baixo nível de rendimento (MORAN, 1981). Assim, a ineficiência econômica e a insustentabilidade ecológica passaram a ser atribuídas mais restritamente à slash-and-burn ou shifting cultivation praticada nas regiões de colonização antiga, como a Zona Bragantina, e nas regiões de colonização nas fronteiras agrícolas. Ali a capacidade de suporte dos agroecossistemas parecia estar próxima do seu limite (ou de já tê-lo transcendido), como conseqüência da crescente densidade demográfica e da integração ao mercado (VALVERDE; DIAS, 1967; BURGER; KITAMURA, 1987; EMBRAPA, 1986).

Na fase da modernização agrícola forçada, a partir dos anos 70, essa avaliação servia para legitimar a promoção unilateral da grande pecuária e das plantações de médio porte de culturas perenes, por meio de grandes subsídios e incentivos fiscais distribuídos pelas agências de desenvolvimento estatais, como a SUDAM e o Banco da Amazônia S.A. (BASA), e por meio da orientação unilateral das atividades de pesquisa e extensão rural da EMBRAPA e da EMATER (HECHT, 1983; FALESI, 1974; BROWDER, 1988).

Porém, a expansão subsidiada da grande pecuária gerou resultados econômicos pobres e levou a uma catástrofe ecológica gigantesca, tendo em vista que mais da metade do desmatamento dos anos 70 e 80 foi produzida pela grande pecuária (SERRÃO; TOLEDO, 1990). A maioria dessas áreas estava num estado tão degradado depois de um ciclo de 6 a 8 anos que foram abandonadas e, com uma densidade média de 0,5 cabeça de gado por hectare, as áreas restantes já não podem ser consideradas rentáveis (BUSCHBACHER; UHL; SERRÃO, 1988). Assim, a pecuária extensiva demonstrou ser apenas uma variedade especial e bastante negativa da shifting cultivation.

Esse fracasso da modernização agrícola baseada nas grandes empresas e nos incentivos fiscais levou as agências estatais SUDAM e EMBRAPA a limitar o desenvolvimento futuro da pecuária à intensificação em áreas degradadas. Sem os subsídios generosos da época anteri- 
or, essa intensificação provavelmente só poderia ser financiada por meio do corte das reservas florestais remanescentes ou por novos programas de crédito subsidiados do FNO (MATTOS; UHL, 1994).

Nos anos 80, com a insustentabilidade da grande pecuária, os programas de modernização agrícola das agências estatais passam a fomentar as culturas perenes em estabelecimentos de médio porte intensivos em capital e, só parcialmente, também na agricultura familiar no Nordeste paraense. Depois de 6 a 8 anos, como no ciclo da pecuária extensiva, o cultivo de culturas perenes - sobretudo no caso da pimentado-reino e do cacau - levou ao aumento drástico de doenças provocadas por fungos e à invasão de ervas daninhas (DENICH, KANASHIRO, 1995). Junto com a queda dos preços no mercado mundial, o segundo pilar da modernização também chegou aos limites agroecológicos e agroeconômicos, o que ainda se agravou pela redução dos programas de apoio estatais.

Assim, ambas as formas de uso da terra - concebidas como alternativas à shifting cultivation - demonstraram ser muito menos duradouras do que se pensava. Apenas no contexto de erosão do atrativo da modernização forçada nos estabelecimentos agrícolas grandes e médios da Amazônia, pesquisadores de agências estatais como a EMBRAPA, num convênio com a GTZ (EMBRAPA, 1986; KITAMURA et al., 1983), a Universidade Federal do Pará (NAEA), o CAT/LASAT em Marabá e o Laboratório Agro-Ecológico da Transamazônica (LAET) em Altamira, foram levados a reconhecer que segmentos dos agricultores itinerantes no Nordeste e no Sul do Pará já haviam se transformado em agriculturas familiares com sistemas de produção mais diferenciados, com uma integração parcial de culturas perenes ou da pecuária.

Apesar do número crescente de pesquisas sobre a pequena agricultura familiar no início dos anos 90, faltava ainda uma distinção clara entre os diversos tipos de pequenos agricultores nas regiões de colonização antiga e nas fronteiras agrícolas de diferentes idades.

Serrão e Homma (1993), em seu artigo escrito para o National Research Council sobre o estado atual da pesquisa e das estratégias de intervenção, acentuam o significado da shifting cultivation para a produção agrícola da região: meio milhão de estabelecimentos é registrado por eles sob esse sistema de uso da terra. Porém, com exceção de algumas poucas diferenciações com respeito à Zona Bragantina, ao Nordeste paraense e às fronteiras agrícolas clássicas, também nesse texto domina o conceito muito rudimentar de uma shifting cultivation que se nutre da fertilidade natural do solo, produzindo rendimentos baixos com métodos manuais, basicamente para a subsistência do pró- 
prio agricultor. Como padrão orientador para o melhoramento e a intensificação dos métodos do cultivo, outras instituições - como o Banco Mundial e o Instituto do Homem e do Meio Ambiente da Amazônia (IMAZON) - fazem referência ao sistema de produção agroflorestal de Tomé-Açu, que é bastante diversificado e artificial, e que combina uma variedade de culturas perenes com um alto uso de mão-de-obra externa e adubo, ou seja, uma intensidade de capital relativamente alta por hectare ou por mão-de-obra (WORLD BANK, 1992; SUBLER; UHL, 1990; TONIOLO; UHL, 1996).

\subsection{A descoberta do campesinato na Amazônia Oriental: agricultores familiares com sistemas de produção e trajetórias diferenciadas}

Os primeiros passos para uma visão mais diferenciada, que ainda não põe em dúvida a tese do ciclo de fronteira e da inerente instabilidade econômica e insustentabilidade ecológica da pequena produção como tendência dominante, foram dados desde o final dos anos 70 numa série de pesquisas no Sul e no Nordeste do Pará.

\subsubsection{O Sul do Pará}

No Sul do Pará, o Centro Agro-Ambiental do Tocantins (CAT), fundado em 1989 em Marabá, e o Laboratório Sócio-Agronômico do Tocantins (LASAT) realizaram trabalhos de pesquisa e desenvolvimento em cooperação com o Groupe de Recherche et d'Échanges Technologiques (GRET) e a Universidade das Antilhas-Guianas, aos quais aplicaram a metodologia francesa dos sistemas agrários para descrever e analisar os sistemas de produção na região de Marabá, que combinaram a produção de arroz, feijão, farinha e milho na roça com uma expansão não esperada da pecuária em lotes bastante grandes (100ha antes de 1980 e 50 ha depois) (CAT, 1992; REYNAL et al., 1996, p. 38).

A estrutura e a dinâmica desses sistemas de produção pesquisados diferiram significativamente da agricultura de subsistência dos "pequenos lavradores", encontrados nos anos 70 por Hébette e Acevedo (1979) nas várias frentes de expansão no Pará e analisados dentro do binômio minifúndio-latifúndio do ciclo de fronteira de uma agricultura itinerante. A monopolização precoce das terras, as políticas públicas em favor dos grandes proprietários, o pequeno tamanho dos lotes, os preços baixos e as condições miseráveis proíbem, na visão 
dos autores, a fixação dos pequenos lavradores na terra, transformando-os temporariamente em peões nas fazendas e causando no final a sua migração para outras áreas rurais ou para as cidades. A única diferença encontrada foram as causas imediatas do êxodo rural: numa colonização dirigida, como na Bragantina, era o minifúndio (25-50ha), que pode garantir a subsistência em regime de agricultura tradicional para uma família jovem, mas não a permanência para a segunda e terceira geração; numa colonização espontânea, como em Imperatriz, o latifúndio é que expulsa os posseiros (HÉBETTE; ACEVEDO, 1979, p. 150, p. 159-160). Outro argumento central ligado ao ciclo de fronteira e muito em voga nos anos 70 foi que a não-rentabilidade microeconômica da agricultura de subsistência, devido aos preços baixos dos alimentos, tem a função vital macroeconômica de acelerar a industrialização (HÉBETTE; ACEVEDO, 1979, p. 171 e p. 187).

Em contraste com essas frentes de expansão dos pequenos lavradores com uma agricultura itinerante de subsistência altamente instável e com itinerários de miséria e expulsão, os autores do CAT/ LASAT encontraram em Marabá frentes pioneiras diversificadas com agricultores familiares "empreendedores", preocupados não somente com sua sobrevivência mas com um itinerário de acumulação patrimonial e trajetórias de evolução rápidas devido a uma "estratégia de fronteira" (REYNAL et al., 1996, p. 3 e p. 51).

No caso específico desses agricultores familiares, as famílias jovens recém-chegadas do Nordeste ou Centro-Oeste instalam-se como agregados ou arrendatários em uma parcela de terra com floresta densa, "acumulam", por meio de lavouras brancas - sobretudo arroz - ou pelo início de criação de gado, o dinheiro suficiente para adquirir um lote próprio para assegurar as necessidades alimentares da família, e sobretudo para aumentar a remuneração do trabalho familiar por meio da implantação de pastos e da criação de gado. Como a produtividade do trabalho na criação de gado é maior em relação às lavouras anuais, a acumulação do gado como reserva de patrimônio estabiliza a situação dos agricultores, otimiza o uso de mão-de-obra familiar e possibilita a entrada numa trajetória de acumulação patrimonial.

Essa começa quando os agricultores alcançam o patamar de 8 a 10 cabeças de gado, que já fornece o capital necessário para expandir a criação e investir nas instalações necessárias, como cercas. As lavouras brancas passam a ter o papel de preparar o terreno para a ampliação das pastagens, que depois de algum tempo rompem o equilíbrio entre lavouras e gado, causando uma "crise da capoeira" que, na verdade, é associada a uma crise de pastagem. Para explicar essa co- 
nexão, os autores mostram que os sistemas de produção baseados somente nas culturas anuais são perfeitamente reprodutíveis quando a área de floresta ou de capoeira é 5 a 7 vezes superior à área cultivada. Como esta última é em média de 3ha, uma área de 15 a 21 ha é o espaço necessário para reproduzir o ciclo das culturas anuais no sistema de corte e queima (ou no caso excepcional de um cultivo de 5ha, entre 25 e $35 \mathrm{ha}$ ), o que se adapta bem ao tamanho dos lotes de $100 \mathrm{ha}$ até 1980 e 50ha depois (REYNAL et al., 1996, p. 38). Mas, como conseqüência da mais alta valorização do trabalho familiar no subsistema gado, os produtores são incentivados a expandir a área de pastagem além desses limites da área necessária para a reprodutibilidade das culturas anuais, o que rompe o equilíbrio inicial entre lavouras e gado. Com um encurtamento do tempo de pousio para 3 anos, a fertilidade do solo e a produtividade das culturas anuais diminuem a tal ponto que as culturas não somente perdem a sua função de acumulação, mas também não podem mais assegurar a base de alimentação que parece ser indispensável ao funcionamento de uma agricultura familiar diversificada. Isso implica uma dependência maior da venda do gado (ou do leite) para cobrir as despesas de manutenção da família, o que implica uma tendência à sobrelotação e ao sobrepastoreio, causando uma "crise técnica" das pastagens. Então, na visão dos autores, a "crise da capoeira" é, na verdade, somente um subproduto da "crise das pastagens".

Para superar essa crise do sistema de produção, os agricultores usam uma "estratégia de fronteira" que consiste na venda de uma parte do "capital gado" para a compra de mais terras dos vizinhos (no caso das localidades recentes) ou na venda da terra valorizada para a aquisição de terras mais baratas em localidades novas e distantes (no caso das localidades antigas). Nos dois casos, os agricultores familiares evitam assim a crise do sistema de produção, provocada pela "crise de capoeira" devido ao aumento desproporcional das pastagens e pela "crise técnica" da pecuária devido à sobrelotação, encontrando, no espaço regional, novas reservas florestais onde podem reproduzir o mesmo esquema de "valorização do meio natural", no desenvolvimento de uma agricultura diversificada ou na especialização no gado.

Essa "estratégia de fronteira" representa, para os agricultores com fraco capital de produção, o melhor meio de valorizar a terra disponível como um dos "maiores trunfos da fronteira" (REYNAL et al., 1996, p. 51). A fronteira constitui então, para os autores, "um espaço econômico em movimento, onde cada um tenta tirar vantagem" e que determinará o ritmo de acumulação e evolução dos sistemas de produção ,que pode 
ser extremamente rápida para alguns, mas, para outros, talvez jamais se concretize.

Para o caso específico de Marabá, os autores do CAT/LASAT chegaram a um modelo explicativo que superou, por um lado, a visão simplificada da agricultura itinerante de culturas alimentícias na fronteira, mostrando a sua viabilidade agroeconômica em lotes acima de 25 ou 30ha. Deixaram ainda evidentes a capacidade empreendedora dos agricultores "pioneiros" em diversificar os sistemas de produção e o seu papel ativo em usar a terra ainda disponível na fronteira como "maiores trunfos" para a superação das crises dos seus sistemas de produção. Em vez de ser só uma frente de subsistência, a fronteira mostrou-se uma frente pioneira com grandes chances de promoção coletiva dos colonos até à formação de um campesinato médio, dotado de patrimônio e meios de produção relativamente elevados (REYNAL et al., 1996, p. 51).

Por outro lado, esse modelo implica também uma reformulação da tese do ciclo de fronteira visto não como expulsão dos agricultores itinerantes pelas empresas capitalistas, mas interpretado como uma estratégia consciente e racional de acumulação patrimonial de gado e terra beneficiada por uma parte dos agricultores familiares, que podem superar a crise da pastagem com a venda da terra valorizada e o deslocamento para novas áreas baratas ainda com floresta densa. Tirada do exemplo específico de Marabá, essa tese reformulada corre o mesmo risco que a tese inicial de generalizar, de uma maneira apressada, uma constelação específica e fornecer apenas uma nova visão homogeneizadora das trajetórias do campesinato na Amazônia. Ademais, essa tese não considera trajetórias diferentes, como a inclusão de culturas perenes, que representam uma alternativa para a expansão desenfreada da pecuária e um potencial de sustentabilidade econômica e ecológica maior. Levando em conta os últimos anos, a dinâmica dos sistemas de produção não seguiu só a trajetória arroz-pastagem, descrita pelos autores, mas incluiu, a partir de 1992, também as culturas perenes (sobretudo o cupuaçu).

Os fundamentos empíricos dessa tese parecem ser duvidosos ou pelo menos precipitados: a "estratégia de fronteira" sugere um deslocamento muito maior, como foi encontrado na própria pesquisa do CAT/LASAT, que constata "uma rotatividade importante" das famílias nos mesmos lotes durante os primeiros 6 anos, de 14\% ao ano, e nas localidades mais antigas (com mais de 20 anos) de 7\% ao ano (REYNAL et al., 1996, p. 30). Comparando essas taxas com a discussão que Ozório de Almeida (1992) faz sobre esse assunto, podemos concluir que essas taxas não são tão altas para falar de uma predominância da estratégia de fronteira como cálculo econômico generalizado. 
A validade geral do modelo da "estratégia de fronteira" sofre fortes dúvidas, considerando o caso da Transamazônica entre Pacajá e Rurópolis, analisados pelo Laboratório Agro-Ecológico da Transamazônica (LAET), porque lá foram encontrados sistemas de produção bem mais diversificados, com um papel preponderante das culturas perenes e só depois, do gado, representando assim trajetórias bem diferentes da estratégia de fronteira (CASTELLANET; SIMÕES; CELESTINO FILHO, 1994). Em vários estudos, pesquisadores franceses do Institut Français de Recherche Scientifique pour le Développement Coopératif (ORSTOM) e brasileiros do Museu Goeldi questionaram a aplicabilidade do ciclo de fronteira a esse caso mas também para Rondônia (HAMELIN, 1992; LÉNA, 1988).

\subsubsection{O Nordeste paraense}

Enquanto o Sul do Pará foi caracterizado por uma imigração mais recente depois da abertura dos novos eixos rodoviários, no Nordeste do Estado a colonização começou no início do século na Zona Bragantina e estendeu-se para a região Guajarina nos anos 40 e 50, bem antes da fase da alta imigração para a Amazônia. Mas foi exatamente esse campesinato à base de uma agricultura itinerante de pousio que serviu como exemplo clássico para a validade do ciclo de fronteira, de alta instabilidade econômica e insustentabilidade ambiental.

Uma série de autores importantes com uma orientação mais biológica, geográfica ou agronômica (CAMARGO, 1948 apud CONCEIÇÃO,1990; CRUZ, 1955; LIMA, 1954; EGLER, 1961; SIOLI, 1951; PENTEADO, 1967) criou a base de observações verdadeiras (o desaparecimento da floresta e a degradação ambiental), mas também superficiais e parciais, como a imagem do pequeno produtor pobre e pouco inteligente:

entregue à rotina sem receber a mínima assistência e orientação técnica, caminha a exemplo do índio, avança eternamente, derruba novas árvores todos os anos, prossegue nômade, mudando sempre de região, produzindo um mínimo com a destruição dessa riqueza secular que a cada passo é deitada abaixo e queimada inconscientemente (CAMARGO, 1948, apud CONCEIÇÃO,1990, p. 8).

Nesse discurso de Felisberto de Camargo, segundo e mais importante diretor do Instituto Agronômico do Norte (IAN) (o antecessor da EMBRAPA Amazônia Oriental), criado por Vargas em 1939 para desenvolver as bases científicas do uso racional das riquezas naturais da 
Amazônia e apresentado na Conferência Inter-Americana de Conservação dos Recursos Renováveis, em Denver, nos Estados Unidos, em setembro de 1948, já foram tocados todos os ingredientes da nova (e velha) visão preconceituosa dos pobres agricultores nômades despreparados, que seguem "o exemplo do índio" e, na "retaguarda do caboclo", "sua obra inconsciente de destruição", "praticando um crime sistematizado" contra o "futuro dos recursos irrenováveis", que, em razão dos "solos excessivamente silicosos num clima tropical úmido", representam um "problema dos mais sérios, morosos e caros para a humanidade" (CAMARGO, 1948 apud CONCEIÇÃO, 1990).

Naturalmente não dá para duvidar do grande mérito de Camargo de enfatizar de forma tão clara e moderna as conseqüências irreversíveis do desmatamento na Amazônia, tomando por base os seus estudos pioneiros sobre a fraqueza dos solos, publicados também em 1948, e o grande peso da produção de lenha e carvão nesse processo. Tampouco é impossível negar seu papel de pioneiro na defesa de culturas perenes como mais apropriadas a estes solos e clima. Mas a apresentação do pequeno produtor como nômade e na "miséria sustentada por uma diminuta produção" foi mais uma representação ideológica da visão tradicional das elites urbanas de Belém que uma descrição correta das formas de produção desse campesinato sedentário que forneceu a Belém alimentos, lenha, matéria-prima (juta, malva, algodão) e mão-de-obra barata, essenciais para a sobrevivência alimentar e para a acumulação mercantil da capital.

Nem todos os autores mencionados, Camargo inclusive, ficaram somente nesse nível de discurso depreciativo. Mas uma reconstrução e uma desconstrução da visão da agricultura itinerante mostram um profundo desconhecimento das formas de produção camponesa e uma tendência nítida de valorizar plantações perenes ou propriedades comerciais mistas de gado leiteiro e culturas de rendimento comercial garantido com a reciclagem do esterco, como a sempre mencionada Granja Imperial, do alemão Rüttelbusch em Marituba (EGLER, 1961, p. 552; SIOLI, 1973, p. 332).

Isso é parcialmente válido para a obra de referência sobre a Bragantina, de Penteado (1967), que apresenta, além de uma enorme riqueza de informações sobre a geografia, os solos, o clima, a produção agrícola e naturalmente os efeitos catastróficos do desmatamento, informações sobre os sistemas de produção agrícola e cálculos que mostram a inviabilidade da agricultura itinerante, computando a mãode-obra familiar a preços de mercado e informações contraditórias sobre a produtividade. Um problema sério é o conceito da agricultura itinerante, que Penteado usa no percurso dos dois volumes sem fazer 
uma distinção explícita de uma agricultura de pousio (as obras essenciais de Boserup, Rappaport, Ruthenberg e muitos outros já tinham sido publicadas). Por isso, ele pode comparar, no primeiro volume, a agricultura itinerante na Bragantina com a "agricultura divagante" dos bantos de Angola, sem entrar nas diferenças fundamentais entre esses dois sistemas (PENTEADO, 1967, p. 96). Isso impede também uma visão conjunta da cultura alimentícia itinerante e da produção comercial de tabaco, malva e algodão como segmentos dos sistemas de produção diferenciados dos pequenos produtores e não de formas aparentemente separadas.

Em seu capítulo final, Penteado resume de novo essa visão predominante na obra dele de uma "agricultura predatória" das lavouras de subsistência ou mesmo comercial com "a falta de um mínimo indispensável à boa utilização do solo", totalmente "empírico" e "arcaico" "sem nenhuma inovação introduzida pelo homem" (PENTEADO, 1967, p. 470). E ele menciona também, de novo, as plantações de pimentado-reino e de seringueira como exemplos de "emprego de técnicas racionais", devido provavelmente ao alto valor desses produtos.

Mas no parágrafo seguinte ele introduz, finalmente, de uma forma quase surpreendente, uma distinção entre agricultura de rotação de terras e itinerância num sentido clássico: os agricultores usam o "sistema clássico da roça e a itinerância das culturas, embora limitada e circunscrita a uma determinada área, conforme já acentuamos, emprestando à paisagem da Bragantina aquele aspecto de desorganização que tão bem a caracteriza" (PENTEADO, 1967, p. 470). Isso significa para Penteado:

Não notamos na área em estudo o nomadismo do homem; embora se pratique a rotação de terras e, raras vezes, a de culturas, o homem encontra-se, mais ou menos, fixado ao solo: nisto reside uma grande diferença entre esse sistema de agricultura da Bragantina e aquele existente na África Tropical (PENTEADO, 1967, p. 470).

Mas esse nomadismo fica circunscrito a uma visão também muito parcial:

Enquanto que no continente africano o agricultor é obrigado a percorrer, diariamente, grandes distâncias, para de sua casa atingir as plantações, os colonos da Bragantina têm-nas imediatamente atrás de suas habitações ou não muito distantes das mesmas (PENTEADO, 1967, p. 470).

Essa distinção leva Penteado a cogitar a possibilidade de "introdução de novos sistemas agrícolas como [...] o uso de corredores que na 
bacia congolesa se mostraram tão eficazes" (PENTEADO, 1967, p. 471). E, em contraste com autores como Sioli, ele reconheceu o fracasso da Granja Imperial do Sr. Ruttelbusch como a alternativa ideal de uma agricultura comercial com um sistema de reciclagem eficiente dos nutrientes, mas com a explicação pouco convincente de que isso se deveu à falta de compreensão dos trabalhadores agrícolas, à legislação trabalhista e ao limitado capital.

Mas essa distinção entre uma agricultura nômade e uma de rotação de terras não afetou a visão geral pessimista e depreciativa de Penteado segundo a qual a irracionalidade dessa agricultura empírica levou a uma destruição do meio ambiente e das condições econômicas de fornecer a Belém os alimentos necessários. Como todos os seus sucessores, ele menciona o aumento populacional drástico para mostrar a inviabilidade da agricultura itinerante primitiva devido ao encurtamento do pousio, sem provar a exata relação entre essas grandezas e até deixando em aberto a resposta, como na seguinte citação:

Resta saber quando a sobrecarga demográfica, cuja pressão aumenta dia a dia, romperá o frágil equilíbrio alimentar em que se encontra a região, pois não existe correlação entre o aumento populacional e a produção agrícola regional, por razões ligadas não somente às condições naturais, mas, e também, ao seu próprio efetivo humano (PENTEADO, 1967, p. 44).

Essas informações parciais, correlações pouco provadas e a visão geral homogeneizadora da obra de Penteado foram raramente discutidas numa forma crítica, mas sempre só repetidas como verdades já provadas.

Um dos problemas metodológicos fundamentais para qualquer estudo sobre o campesinato no Nordeste paraense é a necessidade de livrar-se dessas visões superficiais predominantes, tentando realizar ao mesmo tempo uma revisão da história da colonização e uma reconstrução das estruturas e dinâmicas de desenvolvimento dos sistemas de produção.

Um estudo pioneiro nessa nova ótica foi feito nos anos 70 por Sawyer (1979), em que ele pretende analisar, à base de estudos históricos e empíricos, cuidadosa e realisticamente, as condições que influem na absorção produtiva de migrantes em áreas de fronteira, levando em conta a enorme diversidade das experiências, tanto da colonização espontânea e da agricultura tradicional quanto dos projetos de colonização dirigida na Amazônia, com o fim de superar os preconceitos correntes e as generalizações apressadas. Ele realizou a primeira revisão da história da ocupa- 
ção da Zona Bragantina e de seu prolongamento para a Guajarina desde os anos 40. Em contraste com a visão predominante de Camargo, Penteado e Egler, que já nos anos 50 e 60 falaram dum colapso da Zona Bragantina devido ao aumento da densidade populacional e ao encurtamento do pousio, Sawyer sublinhou, com dados dos censos e outros materiais, que a população rural na Bragantina aumentou com uma taxa anual de 3\% de 1920 a 1940, mas só de 1,3\% de 1940 a 1960; ele mostrou ainda que a produção agrária na Zona Bragantina expandiu-se desde os anos 20 com um grau de comercialização muito alto (no caso da farinha de mandioca, mais de 70\%) e com o cultivo freqüente de produtos comerciais (algodão e malva). Ele põe em dúvida a explicação comum de que a crise da rentabilidade e da produtividade foi causada apenas pela diminuição da fertilidade do solo devido ao desmatamento e ao encurtamento do ciclo de pousio. Na visão dele, fatores econômicos e sociais foram até mais importantes (a Belém-Brasília, o capital mercantil). Partindo de um enfoque da economia familiar, ele criticou cálculos apresentados por Penteado que mostraram perdas financeiras dos colonos na produção da farinha e do milho, sugerindo que isso ocorreu apenas porque a mão-de-obra familiar foi incorretamente computada ao preço de mercado.

Outro mérito de Sawyer foi ter feito a primeira revisão ampla dos conceitos usados e aplicáveis para a análise da pequena produção dos colonos que chegaram do Nordeste para a Zona Bragantina e a Guajarina. Partindo da discussão internacional sobre o campesinato, ele fez uma distinção entre os camponeses de subsistência, dispersos e longe dos centros urbanos (os caboclos e ribeirinhos), e os da pequena produção mercantil perto de cidades e morando mais concentrados ou perto das vilas (os colonos). Dessas duas formas, ele distingue ainda os extrativistas, que muitas vezes também trabalham como assalariados.

No seu estudo particular sobre Capitão Poço, ele discute as tendências para uma diferenciação dos sistemas de produção, a grande capacidade inovadora dos camponeses na introdução da malva, a sua relativa independência do sistema de aviamento e a sua integração altamente flexível no mercado. Mas suas conclusões ainda ficaram presas à visão do ciclo de fronteira, porque Sawyer achava que os camponeses expostos à exploração do capital mercantil e ao declínio da fertilidade do solo não seriam capazes de fazer os investimentos necessários para diversificar os seus sistemas de produção em direção à implementação de pimentais e pastos para o gado.

Só alguns anos depois, uma pesquisa do convênio EMBRAPA/GTZ pôde mostrar que o processo de diferenciação dentro do segmento das 
culturas temporárias avançou muito, que os mercados locais de trabalho tinham um caráter muito dinâmico e que os camponeses mesmos (e não os capitalistas agrários, como Sawyer previa) começaram a implantar os pimentais numa forma inovadora de learning-by-doing e à base dos ingressos monetários da farinha, da malva e do algodão (KITAMURA; HOMMA; FLOHRSCHÜTZ; SANTOS, 1983). Nessa pesquisa, os autores chegaram muito perto do conceito de uma agricultura familiar que não segue a lógica capitalista da microeconomia neoclássica, e perto de uma superação da validade geral do ciclo de fronteira e da identificação da pequena produção com a agricultura migratória, levando em conta a alta estabilidade dos colonos e o alto grau de diferenciação dos sistemas de produção.

Em duas outras pesquisas, os mesmos autores analisaram a expansão da pimenta nas unidades de produção mais capitalizadas dos japoneses em Tomé-Açu e Igarapé-Açu (KITAMURA; HOMMA; FLOHRSCHÜTZ; SANTOS, 1983; FLOHRSCHÜTZ, 1983). Flohrschütz iniciou uma análise interessante sobre custos de reprodução dos camponeses e da estrutura familiar. Um resultado importante dessas duas pesquisas foi que, nesses dois municípios, a expansão das culturas perenes e sobretudo da pimenta concentrou-se mais nos estabelecimentos acima de uma área total média de 80ha, com um grau de capitalização mais elevado. Mas ainda assim os estabelecimentos familiares (abaixo do valor médio) representaram 25\% das entidades pesquisadas. Esse resultado levou provavelmente os autores a considerar a expansão das culturas perenes dentro das unidades da agricultura familiar em Capitão Poço como exceção e não como uma tendência mais geral, apesar do fato de que esses mesmos autores detectaram, numa análise dos dados do Censo Agropecuário de 1980, uma participação de 76,6\% dos estabelecimentos de até 100ha no valor de produção das culturas perenes (BURGER; FLOHRSCHÜTZ, 1984). É pelo menos curioso, porque esses autores generalizaram mais com base nos casos específicos do que nas tendências mais gerais do Censo.

Apesar desses avanços na compreensão empírica da dinâmica dos sistemas de produção no Nordeste paraense, a compreensão teórica não progrediu. Nas pesquisas dentro do convênio EMBRAPA/CPATU-GTZ, constaram processos de diferenciação dos sistemas de produção com a introdução de culturas temporárias comerciais e perenes e, como conseqüência disso, uma certa estabilização econômica e territorial dos agricultores e alguns traços de uma economia familiar diferentes dos modelos neoclássicos. Mas curiosamente esses resultados ficaram soltos porque, apesar de existirem muitos indícios do contrário, não foi 
questionada a validade geral da visão do ciclo de fronteira com uma instabilidade econômica e insustentabilidade ambiental da agricultura migratória (BURGER; KITAMURA，1987; FLOHRSCHÜTZ; KITAMURA, 1986; KITAMURA, 1994).

Isso surpreende, sobretudo porque, pelo menos Burger e Flohrschütz (1984), constataram, num estudo muito interessante com os dados do Censo Agropecuário de 1980 para o Pará, que os pequenos produtores (até 100ha) produziram em somente $20 \%$ da área total dos estabelecimentos rurais 68\% do valor da produção agropecuária total (80\% do valor das culturas temporárias, sobretudo de alimentos básicos, $76,6 \%$ do valor das perenes e 32,6\% do valor da produção animal) e empregaram $82 \%$ das pessoas ocupadas, na maioria familiares (BURGER, FLOHRSCHÜTZ, 1984; BURGER, 1986). Na verdade, nesse mesmo estudo, os autores descreveram com precisão a grande diversidade das tendências na ocupação e utilização das terras e na dinâmica da população rural. Infelizmente, esse enfoque "macro" de análise do papel econômico da pequena produção de até 100ha (e não, como foi feito mais tarde, somente até 50ha) sobreviveu só em algumas citações, como a de Serrão (1995a, 1995b) citada acima, mas nunca foi atualizado nem integrado nos trabalhos seguintes. Na verdade, somente os trabalhos de Costa $(1989,1992,2000)$ e este estudo retomaram e valorizaram essa linha "macro" de pesquisa.

Embora os autores desse convênio apresentem estudos muito valiosos, até a primeira consideração da participação dos pequenos produtores no valor de produção, eles chegaram, no final, como Sawyer, somente a uma reformulação do ciclo de fronteira para o Nordeste do Pará.

Enquanto a versão clássica do ciclo de fronteira enfatiza processos rápidos de imigração seguidos da implantação de culturas anuais, da queda da fertilidade do solo, da conversão das terras em pastos e da venda para seguir para outras fronteiras, na Zona Bragantina constatase uma estabilidade territorial maior, um processo similar de degradação ecológica e econômica, devido ao aumento populacional e à crescente integração ao mercado que leva ao encurtamento contínuo do ciclo de pousio e ao declínio dos preços de mercado. Como essas tendências foram concebidas como lineares, o resultado desse ciclo de fronteira reformulado é o mesmo do modelo clássico: o empobrecimento dos solos e dos colonos que, sem dinheiro para corrigir isso com insumos comprados, vendem as suas áreas para os grandes proprietários para o plantio de culturas perenes ou para a transformação em pastagem, tornandose assalariados rurais ou migrando para a cidade ou para as novas fron- 
teiras agrícolas. Este artigo mostra que todas essas tendências mencionadas somente funcionaram em certos períodos de crise dos sistemas de produção, mas não como tendências lineares e gerais de longo prazo (o que, aliás, seria também impossível apenas do ponto de vista matemático).

Como não parecia possível transferir os resultados do caso de Capitão Poço para os sistemas menos complexos da pequena produção familiar da Zona Bragantina, foram desenvolvidas hipóteses gerais sobre futuros processos de marginalização devido à degradação ecológica, econômica e social (BURGER, KITAMURA, 1987) ou análises neoclássicas que recomendavam um aumento da eficiência por meio da integração em complexos agroindustriais (SANTANA, 1990, 1995).

O estudo de Santana sobre Igarapé-Açu, apesar de ser um dos poucos estudos com grande rigor e uma análise bem sistemática, demonstra os limites de um enfoque baseado na microeconomia neoclássica: o ponto de partida é um processo de integração evolucionário dos pequenos agricultores. Numa primeira fase, eles só cultivam produtos de subsistência para integrar-se paulatinamente, numa segunda fase, à economia de mercado por meio do plantio adicional de culturas perenes, pautando-se por critérios de eficiência econômica. A maioria dos estabelecimentos estudados nessa pesquisa apresenta altas perdas de balanço econômico porque a mão-de-obra familiar utilizada é computada segundo os preços de mercado. Por isso, a superação da economia de subsistência parece só ser possível por meio da integração a complexos agroindustriais, com base em subsídios, e do uso de insumos modernos financiados por meio de créditos. Mas, em contraste com a tese do ciclo de fronteira, esse estudo demonstra também que a pequena produção tende à sua consolidação, embora seja num nível baixo da produtividade do trabalho.

Apesar das críticas metodológicas apresentadas, os resultados do estudo de Santana são importantes. Ele representa uma interpretação neoclássica sofisticada com um entendimento rudimentar das características da economia familiar. Mais importante ainda é que os dados são levantados de forma controlada e representativa, e podem ser também usados para uma interpretação diferente, que constata um alto grau de integração ao mercado até dos microestabelecimentos, o papel central da mão-de-obra familiar e um ciclo de pousio geral de 6 anos.

Em contraste com esse enfoque neoclássico, que analisa a pequena agricultura com as mesmas categorias das empresas capitalistas e abstrai radicalmente as condições ecológicas, é mais adequado usar um enfoque integrado, baseado no debate internacional, que combina a 
economia agrária da agricultura familiar com uma análise dos agroecossistemas, considerando também as dimensões socioculturais (COSTA, 1996a, 1997a; HURTIENNE, 1997).

Esse enfoque da agricultura familiar, que já foi usado em vários trabalhos de Jean Hébette e no Centro Agropecuário da Universidade Federal do Pará (UFPA), no CAT/LASAT em Marabá e no LAET na Transamazônica (que segue o enfoque francês dos sistemas agrários), foi introduzido na Amazônia de maneira mais sistemática pelos trabalhos de Francisco de Assis Costa, do Núcleo de Altos Estudos Amazônicos (NAEA) da UFPA.

\subsection{A estabilização relativa da agricultura familiar por meio da complexificação dos sistemas de produção}

Os trabalhos de Costa romperam, de forma mais definitiva, com a visão do ciclo de fronteira e da agricultura itinerante como tendências predominantes na Amazônia, partindo, por um lado, da base empírica dos dados dos censos agropecuários e dos levantamentos representativos realizados no Nordeste paraense (Uraim, Capitão Poço e Irituia) e, por outro lado, de um modelo teórico mais rigoroso sobre a estrutura e a dinâmica específica da agricultura familiar ou camponesa (COSTA, 1989, 1992, 1996a, 1997a).

O ponto de partida das pesquisas no Nordeste paraense sobre Uraim e Irituia (1989) e Capitão Poço na Guajarina (1993) foi a rejeição do ciclo de fronteira e da agricultura itinerante como tendências predominantes (COSTA, 1996a, 1997a). Os dados do levantamento de 101 estabelecimentos familiares em Capitão Poço foram importantes para a constatação, à primeira vista surpreendente, de que o processo de diferenciação dos sistemas de produção, verificados por Sawyer em 1979 e pelos pesquisadores da EMBRAPA em 1982, avançou depois de 1982 de uma forma tão rápida na direção das culturas perenes e também da pecuária bovina, que Costa poderia falar de uma tendência de complexificação desses sistemas e de uma superação da shifting cultivation pelo sistema de cultivo predominante.

O que Sawyer não poderia imaginar em 1979 e os autores da EMBRAPA só puderam perceber de forma ainda muito embrionária aparentemente aconteceu nos anos 80 , segundo os dados do survey. Os produtores familiares conseguiram superar a crise das culturas anuais desde o final dos anos 70 (devido sobretudo aos preços baixos), mobilizando as suas altas reservas em força de trabalho e intensificando a jornada de trabalho familiar para realizar investimentos na 
implantação das culturas perenes e de pastagem (COSTA, 1996a). Esses investimentos, que alcançaram taxas anuais altas, mas decrescentes (10\% em 1981/85, 7\% entre 1986/90 e 4\% em 1991/93) e que elevaram o valor médio das plantações e pastagens por unidade produtiva de US\$686,00 em 1980 para US\$8.818,00 em 1993, foram, segundo os dados do survey, marginalmente financiados com recursos de terceiros (12\% dos investimentos tiveram alguma participação externa) e realizados fundamentalmente com base no trabalho próprio das famílias. Como resultado dessa dinâmica, inesperada para agricultores familiares, a participação das culturas temporárias no valor de produção bruto em 1993 foi de 17,8\%, superada de longe pelas culturas permanentes (45,5\%) e pela produção animal de 36,7\% (20\% criação de porcos e aves e 16,7\% pecuária bovina) (COSTA, 1996a, p. 14). Descontando os custos, a participação no valor líquido de produção aumentou, no caso das temporárias, para $21,6 \%$ e, da pequena criação, para $25 \%$ e diminuiu para as culturas permanentes $(43,9 \%)$ e para a pecuária bovina (10,6\%) (COSTA, 1997b, p. 15). Como a área das culturas temporárias (577ha) superou a área das permanentes (536ha), o valor líquido por hectare destas últimas ficou muito acima do valor daquelas. No entanto, nos sistemas diferenciados, o rendimento por hectare foi mais baixo do que nos estabelecimentos que só tinham culturas temporárias. Em contrapartida, o rendimento por mão-de-obra familiar foi mais de três vezes maior devido a um aumento similar dos dias trabalhados por trabalhador. Para Costa, isso significa uma trajetória "trabalho-extensiva" e "terra-extensiva" de "eficientização" que privilegia uma maior remuneração anual por unidade da força de trabalho familiar em vez de um aumento do rendimento por unidade da área utilizada ou também por dia trabalhado (COSTA, 1996a, p. 19). Na visão convencional da microeconomia neoclássica, que avalia a eficiência produtiva pela remuneração média (e marginal) de todos os fatores envolvidos, no caso da agricultura da unidade de trabalho (dia, hora) e da terra (ha), essa passagem para sistemas mais diferenciados não é explicável, enquanto numa perspectiva analítica, que leva em conta a racionalidade específica da agricultura familiar para a eficiência reprodutiva, a maior remuneração anual do trabalho familiar é fundamental.

Por isso, no nível teórico-metodológico, Costa ampliou o enfoque da dinâmica interna da agricultura familiar elaborado por Chayanov (1966), que predomina no debate internacional, incluindo, de forma sistemática, os condicionantes estruturais no nível macro e meso, que vêm mais da tradição marxista defendida por Tepicht (1973), num modelo 
da eficiência reprodutiva da agricultura familiar, que deveria explicar melhor tanto os fundamentos das mudanças quanto as razões da estagnação dos padrões reprodutivos dos camponeses:

estratégias de mudança são postas em prática por unidades camponesas sempre que crises no padrão atual de reprodução elevam o nível de 'tensão reprodutiva' a um ponto que é, ao mesmo tempo, suficientemente elevado para tornar agudo e visível o risco da desestruturação definitiva, e não tão extremo que chegue a bloquear [...] a capacidade de desenvolver o esforço extra - quer dizer, acima daquele necessário à reprodução familiar simples - sem a qual a mudança inovativa/adaptativa não poderá existir (COSTA, 1997b, p. 6).

Tais dinâmicas de mudança ou de permanência resultam de "impulsos" provenientes de "uma racionalidade reprodutiva micro", que Costa detecta, à semelhança de Chayanov, no balanço interno da unidade familiar entre insatisfação com o consumo e o grau de fadiga da força de trabalho familiar, que determina as estratégias de reprodução da família por meio de decisões sobre a alocação do tempo na produção de produtos diferentes e a participação do autoconsumo (COSTA, 1994). Essas decisões familiares que dependem, por um lado, da disponibilidade da mão-de-obra familiar e dos fatores de produção terra e capital e, por outro lado, do número dos consumidores, das necessidades culturalmente definidas, do grau da auto-exploração e do grau da aversão ao risco, são fortemente condicionadas pelos fatores "estruturais" em nível macro e meso, como o grau de monopólio (e a taxa de lucro) do capital mercantil, a relação dos preços do produto camponês e dos produtos industriais, e a relação entre produtividade regional e local dos produtos. Enquanto essas forças estruturais tendem a uma deterioração sistemática das condições de reprodução familiar, os esforços familiares orientam-se para uma elevação contínua do rendimento por trabalhador familiar "equivalente" (e não como nos modelos convencionais do rendimento por hectare). Essa luta contínua entre forças estruturais com a tendência para piorar e esforços familiares com a tendência para melhorar as condições de reprodução pode explicar as "tensões reprodutivas" sentidas pelos atores sociais, que não resultam necessariamente numa adaptação passiva às condições estruturais, mas podem também mobilizar esforços extras para mudanças incrementais ou até radicais dos sistemas de produção para superar as crises de reprodução.

Com esse enfoque, Costa quer indicar uma pista para a capacidade bem mais inovadora dos camponeses nesse processo contraditório de adaptações passivas ou mudanças radicais em relação às condições 
estruturais, que implica "investimentos" muito mais à base da intensificação da jornada do trabalho do que do aporte de dinheiro de fora.

Todo esse esforço de modelagem teórico tem, na verdade, o objetivo principal de compreender melhor as tendências observáveis nos dados dos censos agropecuários e dos levantamentos representativos de uma superação da shifting cultivation como propensão primordial no campo para sistemas mais complexos de produção agrícola. Ou, nas palavras de Costa:

mostrar que na Amazônia vem se verificando, desde os anos oitenta, entre os camponeses, um processo claro de reordenamento da base produtiva agrícola: a agricultura itinerante de derruba e queima - a shifting cultivation - vem cedendo lugar a sistemas agrícolas onde as culturas perenes e semiperenes tendem a apresentar importância crescente, ao lado de uma pecuária bovina de pequeno porte e da criação de pequenos animais (COSTA, 1997b, p. 2).

Para Costa, tal dinâmica não se dá de maneira uniforme. Tomando o Pará como referência, podem-se observar nas diversas microrregiões, mas também dentro delas entre os municípios (por exemplo entre Capitão Poço e Irituia, na Guajarina), diferenças consideráveis: enquanto em umas o processo verifica-se em ritmo acelerado, noutras ele acontece em ritmo lento ou, eventualmente, não se manifesta. Numa análise de correlação estatística de um grupo de cinco variáveis com elevado grau de interdependência, Costa encontrou fortes indicações de como os determinantes estruturais têm influído nas diferenças microrregionais da dinâmica de mudança nos estabelecimentos camponeses de até 200 ha: quanto maior a densidade populacional, menor o grau de monopólio do capital mercantil, menor o tamanho médio e a disponibilidade de terra por trabalhador, maior a intensidade de mudança (COSTA, 1997a). Grosso modo, esse processo foi mais forte em áreas de ocupação antiga (Bragantina, Salgado e Baixo Tocantins) e mais fraco em microrregiões que ainda constituem fronteiras recentes (Xingu, Tapajós, Araguaia paraense, Marabá, Guajarina e Médio Amazonas). Mas também dentro da mesma microrregião, como a Guajarina, podem coexistir padrões de mudanças fortes (Capitão Poço) e de estagnação (Irituia), o que Costa tenta explicar com a eficiência reprodutiva maior e tensões reprodutivas menores em Irituia devido à formação de culturas permanentes (nesse caso, o açaí) bem mais cedo, com um autoconsumo mais alto, um rendimento por área maior e trabalho despendido em dias/homem bem mais baixo do que em Capitão Poço (COSTA, 1997b, p. 23).

Mas, apesar dessas ressalvas e diferenciações mais recentes, Costa chegou a formular, à base desse duplo esforço teórico e empírico, a 
tese de uma relativa estabilização do campesinato no Pará e na Amazônia como tendência predominante e como contraponto às visões apresentadas. Com essa tese, apresentada como válida para toda a Amazônia, Costa corre o risco de postular uma tendência homogeneizadora que não se adapta bem aos resultados mais diferenciados do último Censo Agropecuário de 1995/96.

No nível operacional, Costa propõe um critério simples para a distinção da agricultura familiar: são considerados familiares os estabelecimentos onde, segundo os dados do Censo, a participação da mão-de-obra familiar não remunerada no conjunto do pessoal ocupado supera 90\% (COSTA, 1992, p. 18). No caso do Pará e dos outros estados do Norte, os estabelecimentos de até 200 ha cumpriram esse critério em 1985 (COSTA, 1992, p. 17; COSTA, 1997a, p. 7). Segundo esse critério, 96\% dos estabelecimentos agrícolas na região Norte foram considerados familiares, com uma área total de 16,8 milhões de hectares (37,6\% da área total dos estabelecimentos) e 2,05 milhões de pessoas ocupadas (92\%), um valor de produção que chegou a representar 73,5\% do valor de produção agropecuário da região Norte (90\% do valor das temporárias, 84,6\% das permanentes e 46,2\% da pecuária) (COSTA, 1997a).

Num enfoque comparável ao de Costa quanto à caracterização da agricultura familiar, os autores do convênio United Nations Food and Agriculture Organization (FAO)/INCRA (1996a), entre eles Veiga, Abramovay e Romeiro, desenvolveram critérios operacionais diferentes para definir estabelecimentos familiares. Levando em conta que a experiência empírica indica a existência de empresas familiares que contam com trabalho assalariado complementar (inclusive permanente), bem como de empresas patronais que podem ser equivocadamente classificadas como familiares quando seus assalariados estão encobertos por contratos de empreitada, os autores optaram por critérios que provavelmente superestimam o conjunto patronal: a) a direção da unidade é exercida pelo produtor; b) não foram realizadas despesas com serviços de empreitada; c) não há empregados permanentes e o número médio de empregados temporários é inferior ou igual a quatro ou há um empregado permanente e o número médio de empregados temporários é inferior ou igual a três; d) a área total é inferior ou igual a 500ha no Sudeste e Sul e a 1000ha nas demais regiões.

Segundo esses critérios, em 1995, 85\% dos estabelecimentos agrícolas na região Norte foram considerados como familiares, com uma área total de 21,9 milhões de hectares (37,5\% da área total dos estabelecimentos) e 1,5 milhão de pessoas (82,2\%), um valor de pro- 
dução que chegou a representar 58\% do valor de produção agropecuária da região (84\% da mandioca, 73,3\% do milho, 63\% das aves e $53 \%$ do arroz). A renda média calculada para o ano de 1995, em salários mínimos (SM), foi mais alta do que se tinha esperado. A renda monetária bruta (RMB) por ano alcançou a média de 22 salários mínimos por família e 5,2 salários mínimos por pessoa ocupada. Atrás dessa média, encontram-se condições de renda bem diferentes (FAO/INCRA, 1996b):

- os produtores "consolidados" do grupo A (30\% dos estabelecimentos, com 62\% do valor de produção e uma área média de 60ha) têm uma renda monetária bruta de 55SM por ano;

- os produtores "intermediários" ou "em transição" do grupo B (21\% dos estabelecimentos com 17\% do valor de produção e uma área média de 40ha) têm uma renda monetária de 17SM;

- os produtores "periféricos" do grupo C (50\% dos estabelecimentos com $21 \%$ do valor da produção e uma área média de 37ha) têm uma renda monetária de 4SM por ano.

\subsection{Agricultura familiar e desenvolvimento rural sustentável: uma perspectiva para futuras pesquisas}

A integração sistemática das formas de uso da terra, os seus graus de sustentabilidade e as perspectivas para um manejo sustentável dos recursos naturais encontram-se num estádio ainda pouco explorado nos trabalhos socioeconômicos sobre a dinâmica da ocupação das terras, da formação de um campesinato e a diferenciação dos sistemas de produção. Os estudos do IMAZON formam uma exceção, mas não conseguem ainda elaborar um marco de análise satisfatório para a inter-relação entre usos de recursos naturais e formas econômicas de produção ou extração no âmbito da pequena produção (ALMEIDA, 1996). Isso se deve ao uso exclusivo do instrumental da análise microeconômica de porte neoclássico para formas de produção que diferem de empresas capitalistas, à falta de clareza sobre os diversos níveis e graus de sustentabilidade ambiental e a um enfoque mais diferenciado e operacional dos processos de decisão socioeconômicos, que afetam os impactos ambientais e são por eles afetados.

Trabalhos sobre a pequena produção deveriam incluir sistematicamente as diversas formas de uso ou manejo de recursos naturais no ciclo de pousio na tradição de Boserup (1965) e Ruthenberg (1980). Assim se diferenciariam da microeconomia neoclássica, que analisa a 
pequena produção com as mesmas categorias aplicadas às empresas agrícolas capitalistas, que levam ao resultado paradoxal de balanços anuais negativos devido à computação da mão-de-obra familiar com base nos salários pagos no mercado de trabalho, e reduz os cálculos dos agricultores à eficiência produtiva da terra e do dia trabalhado e, numa versão mais sofisticada, à redução de riscos.

Contrastando com isso, o enfoque da agricultura familiar permite distinguir objetivos diversos sob condições de uma racionalidade de ação limitada ou contraditória (bounded rationality) que são ligados a dimensões diferentes dentro da unidade familiar. Na área da segurança alimentar, predominam estratégias de médio e longo prazos de sobrevivência, redução de risco, valorização do autoconsumo e, conseqüentemente, da "alternatividade" do "cálculo camponês" na produção de alimentos (HEREDIA, 1979; GARCIA JR., 1983, 1990). Com os dados da pesquisa de Costa, foi possível detectar essa tendência até para o caso de Capitão Poço: apesar do fato de que as culturas temporárias (sobretudo a mandioca) tinham rendimentos anuais por hectare, por dia trabalhado e por unidade de mão-de-obra familiar bem inferiores aos das culturas perenes, os camponeses alocaram na média o dobro de dias trabalhados naqueles cultivos em relação às perenes, aparentemente mais rentáveis. Também quando se inclui, como Costa, o alto valor da pequena criação no das culturas temporárias, não se alcançam os valores das permanentes, a não ser que se desconsiderem as árvores frutíferas do quintal (cálculos próprios com base nos dados de Costa, 1997b). Provavelmente é mais plausível não partir de um único cálculo camponês, mas levar em consideração pesos diferentes para a segurança alimentar em qualquer ano, o que formalmente se pode fazer levando em conta um prêmio de risco.

Na área do ingresso monetário anual familiar, pode dominar uma estratégia de maximização de curto prazo (aproveitando preços melhores e chances inesperadas de mercado) que, nas condições do processo de trabalho agrícola, leva tempo e, por isso, normalmente não se distingue da maximização do rendimento anual por unidade do trabalho familiar (e não da área ou da hora trabalhada). Já na área do melhoramento a longo prazo da situação econômica, predomina uma orientação de investimentos mais arriscados em plantações de culturas perenes, pastos e acumulação patrimonial de gado (OZÓRIO DE ALMEIDA et al., 1992).

Ainda não é possível dizer muito sobre o peso relativo desses cálculos econômicos conflitantes na tomada de decisão na agricultura familiar na Amazônia, porque poucos modelos e trabalhos empíricos abordaram esses cálculos de maneira sistemática (KITAMURA et al., 1983; 
OZÓRIO DE ALMEIDA, 1992; OZÓRIO DE ALMEIDA et al., 1992; SANTANA, 1990; ELLIS, 1993; COSTA, 1994, 1997a). Um melhor esclarecimento dos processos de tomada de decisão na pequena produção é fundamental também para a aplicação prática de recomendações, como as do projeto SHIFT Capoeira, de priorizar vantagens de médio prazo em detrimento das vantagens de curto prazo, neste caso, eliminar o uso do fogo como técnica de fertilização, o que diminui a perda de nutrientes da capoeira a médio e a longo prazos, mas implica também gastos maiores para a compra de adubo no primeiro ano para compensar esse efeito (KATO et al., 1999).

O esclarecimento das estruturas mistas dos cálculos socioeconômicos dos pequenos agricultores poderia indicar uma zona de convergência entre sustentabilidade ecológica, consolidação econômica e um melhoramento das condições de vida.

Nesse sentido, o fato de a pesquisa concentrar-se nas características da agricultura familiar como ponto de partida não exclui a consideração de opções para a mão-de-obra familiar no mercado local e regional de trabalho, incluindo os cálculos das vantagens comparativas. Em contraste com os modelos de farm-household, o nosso enfoque assume o uso limitado, não generalizado, de cálculos de custos de oportunidade. Dessa maneira, evita-se o problema de não poder explicar, por exemplo, a produção contínua de mandioca, embora isso signifique balanços anuais negativos (KITAMURA, 1982). Esse enfoque também não exclui o uso temporário de mão-de-obra externa. O elemento central do enfoque é a substituição dos cálculos de rentabilidade convencionais (por exemplo, rendimento por hectare e por dia de trabalho) pelo rendimento anual bruto ou líquido por mão-de-obra familiar como eixo das decisões na agricultura familiar (COSTA, 1994).

Além disso, a construção das estruturas de tomada de decisão na agricultura familiar sob condições agroecológicas e socioeconômicas variáveis também requer um enfoque metodológico mais amplo que transgrida os limites da sua análise. É preciso considerar tanto a dimensão histórica do desenvolvimento de sistemas de cultivo e produção no contexto dos fatores de influência socioeconômica e das características agroecológicas de um sistema agrícola regional, como também os cálculos de custos e benefícios relacionados a essas condições. O enfoque francês do sistema de produção (MAZOYER, 1987; DUFUMIER, 1996) oferece essa possibilidade de combinar a economia agrícola com a análise de agroecossistemas. 


\section{CONCLUSÕES}

Fora de uma discussão sobre o impacto da agricultura familiar no desmatamento, foram principalmente apresentadas duas visões opostas da agricultura familiar na Amazônia: a visão dominante do ciclo de fronteira e a da estabilização dos camponeses com base na complexificação dos sistemas de produção. Como a discussão das pesquisas mostrou, essa contradição nas perspectivas de análise pode ser explicada, à primeira vista, pelas diferenças significantes e contraditórias, por um lado, entre as zonas de colonização mais antigas, como a Bragantina e seu prolongamento até a região Guajarina, no Nordeste paraense, que surgiram antes da construção da Belém-Brasília (Capitão Poço, Irituia) e onde prevaleceu desde o início uma tendência à estabilização relativa; por outro lado, nas zonas de colonização mais recente na Amazônia ocidental (Rondônia, Mato Grosso) e no Sul do Pará (Marabá, Transamazônica), que surgiram depois da Belém-Brasília, o ciclo da fronteira parece ter mais evidência.

Mas a discussão das várias pesquisas mostrou também que a escolha do enfoque de análise em geral foi bem mais importante do que as diferenças observáveis na realidade estudada. Essa escolha ficou muito enraizada e ancorada na visão predominante, segundo a qual os atores sociais no campo são um "problema social" e um impedimento para o progresso desde a colonização. A noção de agricultura itinerante como necessariamente predatória, arcaica e irracional permaneceu desde o século passado até as formulações mais científicas nos anos 70, por Penteado. O veredicto dos modernizadores dos anos 70, como Reis Velloso, e as visões não tão diferentes do Banco Mundial demonstram o enorme peso das noções ideológicas das elites comerciais urbanas amazônicas e a sua visão distorcida de um mundo rural nunca bem entendido. Infelizmente, durante muito tempo, pesquisadores bem-intencionados não conseguiram livrar-se dessa bagagem de um passado colonizador, porque as evidências superficiais do uso do fogo numa agricultura de derruba e queima aparentemente sustentaram essa visão.

A conclusão do trabalho sobre os problemas conceituais e metodológicos não é negar os problemas evidentes da sustentabilidade ambiental, econômica e social dos produtores familiares na Amazônia, mas

ajudar num processo de auto-reflexão da comunidade dos pesquisadores e assumir o desafio de um trabalho verdadeiramente científico, mas, ao mesmo tempo, engajado, para compreender melhor a diversidade social no campo da Amazônia, como ponto de partida para estratégias mais adequadas a um desenvolvimento rural sustentável. 


\section{REFERÊNCIAS}

ABRAMOVAY, R. Paradigmas do capitalismo agrário em questão. São Paulo: HUCITEC/UNICAMP; Rio de Janeiro: ANPOCS, 1992.

. De volta para o futuro: mudanças recentes na agricultura familiar. In: SEMINÁRIO NACIONAL DO PROGRAMA DE PESQUISA EM AGRICULTURA FAMILIAR DA EMBRAPA, 1., 1997, Petrolina. Anais... Petrolina: EMBRAPA, 1997. p. 17-27.

AlmEIDA, O. T. (Org.). A evolução da fronteira amazônica: oportunidades para um desenvolvimento sustentável. Porto Alegre: Edições Caravela; Belém: IMAZON, 1996.

AUBERTIN, C. (Org.). Fronteiras. Brasília: UNB/ORSTOM, 1988.

BECKER, B.; MIRANDA, M.; MACHADO, L. (Org.). Fronteira amazônica: questões sobre a gestão do território. Brasília: UNB/UFRJ, 1990.

BOSERUP, E. The conditions of agricultural growth: the economics of agrarian change under population pressure. Chicago: Aldine, 1965.

BROWDER, J. Public policy and deforestation in the Brazilian Amazon. In: REPETTO, R.; GILLIS, M. (Org.). Public policies and the misuse of forest resources. Cambridge, Mass.: WRI, 1988. p. 247-298.

BURGER, D. O uso da terra na Amazônia oriental. In: CPATU-EMBRAPA/ GTZ. Pesquisas sobre utilização e conservação do solo na Amazônia oriental. Belém, 1986. p. 69-93.

; FLOHRSCHÜTZ, G. A estrutura do setor agrário da Amazônia oriental. In: SIMPÓSIO DO TRÓPICO ÚMIDO, 1984, BELÉM. Anais... Belém: CPATU-EMBRAPA, 1984, v. 1.

; KITAMURA, P. Importância e viabilidade de uma pequena agricultura sustentada na Amazônia oriental. In: KOHLHEPP, G.; SCHRADER, A. (Org.). Homem e natureza na Amazônia. Tübingen: Geographisches Institut der Universität Tübingen, 1987.

BUSCHBACHER, R.; UHL, C.; SERRÃO, E. A. S. Abandoned pasture in Eastern Amazonia: nutrient stocks in the soil and vegetation. J. Ecol., Blackwell, n. 76, p. 682-699, 1988. 
CASTELLANET, C.; SIMÕES, A.; CELESTINO FILHO, P. Diagnóstico preliminar da agricultura familiar na Transamazônica: pistas para pesquisa-desenvolvimento. Seminário do CPATU. Palestra. 1994.

CENTRO AGRO-AMBIENTAL DO TOCANTINS. Elementos de análise do funcionamento dos estabelecimentos familiares da região de Marabá. Marabá: CAT, 1992.

CHAYANOV, A. V. The theory of peasant economy. Homewood, Ill.: Irwin, 1966.

CONCEIÇÃO, M. Políticas e colonos na Bragantina, estado do Pará: um trem, a terra e a mandioca. 1990. 319f. Dissertação (Mestrado em Sociologia) - Universidade Estadual de Campinas, Campinas, 1990.

COSTA, F. Amazonien - Bauern, Märkte und Kapitalakkumulation. Saarbrücken, Fort Lauderdale: Breitenbach, 1989.

. Ecologismo e questão agrária na Amazônia. Belém: NAEA/ UFPA, 1992.

- Racionalidade camponesa e sustentabilidade: elementos teóricos para uma pesquisa sobre agricultura familiar na Amazônia. Belém: NAEA/UFPA, 1994. (Paper do NAEA, n. 12)

Agricultura familiar em transformação na Amazônia: o caso de Capitão Poço e suas implicações para a política e o planejamento agrícola regional. Revista Econômica do Nordeste, Fortaleza, v. 27, n. 4, p. 633672, 1996a.

Diversidade estrutural e desenvolvimento sustentável: novos supostos de política de planejamento agrícola para a Amazônia. In: XIMENES, T. (Org.). Perspectivas do desenvolvimento sustentável: uma contribuição para a Amazônia 21. Belém: NAEA/UFPA, 1997a. p. 225-270.

. O açaí nos padrões de reprodução de camponeses agrícolas do Nordeste paraense: os casos de Capitão Poço e Irituia. Paper do NAEA, n. 76, Belém, 1997b 
. Contexto, impactos e efeitos econômicos do FNO-Especial no estado do Pará. In: TURA, L.; COSTA, F. (Org.). Campesinato e Estado na Amazônia: impactos do FNO no Pará. Belém: FASE, 2000. p. 225-270.

COY, M. Rondônia: frente pioneira e Programa Polonoroeste. In: KOHLHEPP, G.; SCHRADER, A. (Org.). Homem e natureza na Amazônia. Tübingen: Geographisches Institut der Universität Tübingen, 1987.

. Desenvolvimento regional na periferia amazônica: o caso de Rondônia. In: AUBERTIN, C. (Org.). Fronteiras. Brasília: UNB/ORSTROM, 1988. p. 167-194.

CRUZ, E. A Estrada de Ferro de Bragança: visão social, econômica e política. Belém: [s.n.], 1955.

DENICH, M.; KANASHIRO, M. A vegetação secundária na paisagem agrícola do Nordeste Paraense, Brasil. In: WORKSHOP INTERNACIONAL DE SANTARÉM, 1995, Santarém. Anais... Santarém: [s.n.], 1995. p. 14-24.

; KANASHIRO, M.; VLEK, P. L. The potential and dynamics of carbon sequestration in traditional and modified fallow systems of the Eastern Amazon Region, Brazil. In: LAL, R.; KIMBLE, J. M.; STEWART, B. H. (Ed.). Advances in soil science, special issue. Global climate change and tropical ecosystems. [S.1.: s.n.], 2000. p. 213-230.

DUFUMIER, M. Les projets de développement agricole. Paris: CTA; Wageningen: Karthala, 1996.

EGLER, E. G. Zona Bragantina no estado do Pará. Revista Brasileira de Geografia, Rio de Janeiro, n. 23, p. 527-555, 1961.

ELLIS, F. Peasant economics: farm households and agrarian development. Cambridge: Cambridge University Press, 1993.

EMBRAPA. Pesquisas sobre utilização e conservação do solo na Amazônia oriental. Belém: EMBRAPA-CPATU/GTZ, 1986 (Documento 40).

FALESI, I. C. O solo da Amazônia e sua relação com a definição de sistemas de produção agrícola. Brasília: EMBRAPA/IICA, 1974 (Documento 2). 
FAO/INCRA. Perfil da agricultura familiar no Brasil: dossiê estatístico. Projeto UFT/BRA/036/BRA. [S.l.: s.n.], 1996a.

A agricultura familiar na região Norte. Brasília: Projeto UFT/ BRA/036/BRA. [S.1.: s.n.], 1996b.

FEARNSIDE, P. Quem está desmatando a Amazônia: os ricos ou os pobres? Ciência Hoje, v. 10, n. 113, 1995. p. 27-33.

FLOHRSCHÜTZ, G. Análise econômica de estabelecimentos rurais no município de Tomé-Açu, Pará: um estudo de caso. Belém: EMBRAPACPATU, 1983 (Documento 19).

; KITAMURA, P. A pequena agricultura na Amazônia oriental. In: EMBRAPA-CPATU/GTZ. Pesquisas sobre utilização e conservação do solo na Amazônia oriental. Belém, 1986. p. 95-112.

FOWERAKER, J. The struggle for land: a political economy of the pioneer frontier in Brazil from 1930 to the present day. Cambridge: Cambridge University Press, 1981.

FRIEDMANN, H. Household Production and the national economy: concepts for the analysis of agrarian formations. Journal of Peasant Studies, London, v. 7, n. 2, p. 158-184, 1980.

GARCIA JR., A. Terra de trabalho. Rio de Janeiro: Paz e Terra, 1983.

O Sul: caminho do roçado. São Paulo: Marco Zero/UNB, 1990.

HAMELIN, P. O fracasso anunciado. In: LÉNA, P.; OLIVEIRA, A. (Org.). Amazônia: a fronteira agrícola 20 anos depois. Belém: Cejup/MPEG, 1992. p. 161-176.

HÉBETTE, J.; ACEVEDO, R. Colonização espontânea, política agrária e grupos sociais. In: COSTA, J. M. M. (Org.). Amazônia: desenvolvimento e ocupação. Rio de Janeiro: IPEA/INPES, 1979. p. 141-191.

HECHT, S. Cattle ranching in Eastern Amazonia: environmental and social implications. In: MORAN, E. F. (Org.). The dilemma of Amazonian development. Boulder, Col.: Westview Press, 1983. p. 155-188. 
HEREDIA, B. A morada da vida. Rio de Janeiro: Paz e Terra, 1979.

HOMMA, A. A extração de recursos naturais renováveis: o caso do extrativismo vegetal na Amazônia. Viçosa: Universidade Federal de Viçosa, 1989.

; WALKER, R. et al. Redução dos desmatamentos na Amazônia: política agrícola ou ambiental. In: HOMMA, A. (Org.). Amazônia: meio ambiente e desenvolvimento agrícola. Brasília: EMBRAPA, 1998. p. 119-143.

HURTIENNE, T. Tropenökologie und kleinbäuerliche Landnutzungssysteme in Ostamazonien. Belém, 1997. Mimeografado.

. Tropical ecology and peasant agriculture in the Eastern Amazon: a comparison of results of socio-economic research on agrarian frontiers with diverse historical and agro-ecological conditions. In: LIEBEREI, R.; BIANCHI, H. K.; Voß, K. (Org.). Proceedings of the Third SHIFT Workshop. Manaus; Geesthacht, 1998. p. 203-217.

- Agricultura familiar na Amazônia oriental. Novos Cadernos do NAEA, v. 2, n. 1, Belém, 1999. p. 75-94.

. Peasant agriculture and differing land use patterns in the Eastern Amazon. In: CONGRESSO MUNDIAL DE SOCIOLOGIA RURAL, 10., 2000, Rio de Janeiro. Anais ... Rio de Janeiro, 2000. 1 CD-ROM.

IBGE. Censo Demográfico de 1991. Disponível em: <http:// www.ibge.gov.br>. 1 CD-ROM.

. Censo Demográfico de 1996. Dispon[ivel em: <http:// www.ibge.gov.br>. 1 CD-ROM.

Censo Agropecuário do Pará - 1995/1996. Rio de Janeiro: IBGE, 1998.1 CD-ROM.

INPE. Monitoramento da floresta amazônica brasileira por satélite - 1998/1999. Brasília: INPE, 2000.

IPARDES. Conseqüências sociais das transformações tecnológicas na agricultura do Paraná. In: MARTINE, G.; GARCIA, R. C. (Org.). Os impactos sociais da modernização agrícola. São Paulo: Caetés, 1987. p. 125-167. 
KATO, M. S.; KATO, O. R.; DENICH, M.; VLEK, P.L. Fire-free alternatives to slash-and-burn for shifting cultivation in the Eastern Amazon Region: the role of fertilizers. Field Crops Research, Elsevier Science B. V., n. 62, p. 225-237, 1999.

KITAMURA, P. Agricultura migratória na Amazônia: um sistema de produção viável. Belém: EMBRAPA-CPATU, 1982 (Documento 12).

A Amazônia e o desenvolvimento sustentável. Brasília: EMBRAPA-SPI, 1994.

; HOMMA, A.; FLOHRSCHÜTZ, G.; SANTOS, A. dos. A pequena agricultura no Nordeste Paraense. Belém: EMBRAPA-CPATU, 1983.

LÉNA, P. Diversidade da Fronteira Agrícola na Amazônia. In: AUBERTIN, C. (Org.). Fronteiras. Brasília: UNB/ORSTOM, 1988. p. 90-129.

; OLIVEIRA, A. (Org.). Amazônia: a fronteira agrícola 20 anos depois. Belém: Cejup/MPEG, 1992.

LIMA, R. A. A agricultura nas várzeas do estuário do Amazonas. Boletim Técnico do Instituto Agronômico do Norte, Belém, v. 33, p. 1-64, 1956.

Rondônia and the fate of small farmers. In: GOODMAN, D.; HALL, A. (Org.). The future of Amazonia: destruction or sustainable development? London: Macmillan, 1990. p. 23-48.

MATTOS, A.; UHL, C. Economic and ecological perspectives on ranching in the Eastern Amazon. World Development, Elsevier Science B. V., v. 22, n. 2, p. 145-158, 1994.

MAZOYER, M. Dynamique des systèmes agraires: rapport de synthèse du colloque sur la dynamique des systèmes agraires. Paris: Ministère de la Recherche et de la Technologie, 1987.

MORAN, E. F. Developing the Amazon. Bloomington: Indiana University Press, 1981.

et al. Restoration of vegetation cover in the Eastern Amazon. Ecological Economics, Elsevier Science B. V., v. 18, n. 1, p. 41-54, 1996. 
NEPSTAD, D. Empobrecimento biológico da Floresta Amazônica por seringueiros, madeireiros e fazendeiros. In: XIMENES, T. (Org.). Perspectivas do desenvolvimento sustentável: uma contribuição para a Amazônia 21. Belém: NAEA/UNAMAZ, 1997. p. 311-334.

et al. The role of deep roots in the hydrological and carbon cycles of Amazonian forests and pastures. Nature, Elsevier Science B. V, n. 372, p. 666-669, 1994.

; MOREIRA, A.; ALENCAR, A. A floresta em chamas: origens, impactos e prevenção de fogo na Amazônia. Brasília: PPG7, 1999.

OZORIO DE ALMEIDA, A. L. Colonização dirigida na Amazônia. Rio de Janeiro: IPEA, 1992.

; CAMPARI, J. S. Sustainable settlement in the Brazilian Amazon. Washington, Oxford: World Bank, Oxford University Press, 1995.

; SANTOS, A.; ALVES, A.; MORAIS, M. A colonização sustentável da Amazônia. Brasilia: IPEA, 1992 (Texto para discussão, n. 266).

PENTEADO, A. R. Problemas de colonização e uso da terra na Região Bragantina do estado do Pará. Belém: UFPA, 1967. 2 v.

REYNAL, V. de.; MUChAGATA, A. G.; TOPAlL, O.; HÉBETTE, J. Agriculturas familiares e desenvolvimento em frente pioneira amazônica. Belém: LASAT/CAT, 1996.

RUTHENBERG, H. Farming systems in the Tropics. Oxford: Clarendon Press, 1980.

SANTANA, A. C. Diagnóstico socioeconômico da pequena agricultura de Igarapé-Açu. Belém: FCAP, 1990. Relatório de pesquisa.

SAWYER, D. Colonização da Amazônia: migração de nordestinos para uma frente agrícola no Pará. Revista de Economia do Nordeste, Fortaleza, v. 10, n. 3, p. 773-812, 1979.

. Frontier expansion and retraction in Brazil. In: SCHMINK, M.; WOOD, C. (Org.). Frontier expansion in Amazonia. Gainsville/Florida: [s.n.], 1984. p. 180-203. 
SCHNEIDER, R. Government and the economy on an Amazon frontier. Washington: World Bank, 1995.

SERRÃO, E. A. S. Desenvolvimento agropecuário e florestal na Amazônia. In: COSTA, J. M. M. da (Org.). Amazônia: desenvolvimento econômico, desenvolvimento sustentável e sustentabilidade de recursos naturais. Belém: Cejup, 1995a. p. 57-104.

. Possibilities for sustainable agriculture development in the Brazilian Amazon: an EMBRAPA Proposal. In: CLÜSENER-GODT, M.; SACHS, I. (Org.). Brazilian perspectives on sustainable development of the Amazon Region. Paris: UNESCO. Man and the Biosphere Series, v. 15, 1995b. p. 259-263.

; HOMMA, A. Brazil Country Profile. In: NATIONAL RESEARCH COUNCIL (Org.). Sustainable agriculture and the environment in the Humid Tropics. Washington D.C.: National Academy Press, 1993. p. 263351.

; NEPSTAD, D.; WALKER, R. Desenvolvimento agropecuário e florestal de terra firme na Amazônia. In: HOMMA, A. (Org.). Amazônia: meio ambiente e desenvolvimento agrícola. Brasília: EMBRAPA, 1998. p. 367-386.

; TOLEDO, J. The search for sustainability in Amazonian pastures. In: ANDERSON, A. (Org.). Alternatives to deforestation. New York: Columbia University Press, 1990. p. 195-214.

SIOLI, H. Estudo preliminar das relações entre a geologia e a limnologia da Zona Bragantina. Belém: IAN, 1951 (Boletim Técnico 24).

. Recent human activities in the Brazilian Amazon Region and their ecological effects. In: MEGGERS, B. J.; AYENSU, E. S.; DUCKWORTH, W. D. (Org.). Tropical forest ecosystems in Africa and South America: a comparative revue. Washington, D.C.: Smithsonian Inst. Press, 1973. p. 321-334.

SUBLER, S.; UHL, C. Japanese agroforestry in Amazonia: a case study in Tomé-Açu. In: ANDERSON, A. (Org.). Alternatives to deforestation: steps towards sustainable use of the Amazon Rain Forest. New York: Columbia University Press, 1990. p. 152-166.

TEPICHT, J. Marxisme et agriculture: le paysan polonais. Paris: Armand Colin, 1973. 
TONIOLO, A.; UHL, C. Perspectivas econômicas e ecológicas da agricultura na Amazônia oriental. In: ALMEIDA, O. T. (Org.). A evolução da fronteira amazônica: oportunidades para um desenvolvimento sustentável. Belém: IMAZON, 1996. p. 67-100.

VALVERDE, O.; DIAS, C. A rodovia Belém-Brasília. Rio de Janeiro: FIBGE, 1967.

VEIGA, J. E. O desenvolvimento agrícola: uma visão histórica. São Paulo: EDUSP/HUCITEC, 1991.

VELHO, O. Capitalismo autoritário e campesinato. São Paulo; Rio de Janeiro: Difel, 1976.

WAGLEY, C. Amazon town. New York: Macmillan, 1953.

WALKER, R. et al. A evolução da cobertura do solo nas áreas de pequenos produtores na Transamazônica. In: HOMMA, A. (Org.). Amazônia: meio ambiente e desenvolvimento agrícola. Brasília: EMBRAPA, 1998. p. 321-343.

WORLD BANK. Brazil: an analysis of environmental problems in the Amazon. Washington: World Bank, Country Operations Division, Brazil Department, 1992. 